\title{
Dynamical Relationship between Quasi-stationary Rossby Wave Propagation along the Asian Jet and Pacific-Japan Pattern in Boreal Summer
}

\author{
Kazuto TAKEMURA \\ Graduate School of Science, Kyoto University, Kyoto, Japan \\ Climate Prediction Division, Japan Meteorological Agency, Tokyo, Japan \\ and \\ Hitoshi MUKOUGAWA \\ Graduate School of Science, Kyoto University, Kyoto, Japan
}

(Manuscript received 7 August 2019, in final form 1 Nobember 2019)

\begin{abstract}
This study investigates a new possible process linking the quasi-stationary Rossby wave propagation (SWP) over Eurasia along the Asian jet and the Pacific-Japan (PJ) pattern through the Rossby wave breaking (RWB) near the jet exit region during boreal summer using a reanalysis dataset. To assess the statistical significance of the process, we conduct a lag composite analysis of the past 44 RWB events east of Japan. The result of the lag composite analysis shows that the SWP along the Asian jet induces the RWB accompanied by an amplified anomalous anticyclone east of Japan. The associated "inverse-S" shaped overturning of the upper-level potential vorticity (PV) distribution causes the southwestward intrusion of the high PV toward the subtropical western North Pacific (WNP). The $\boldsymbol{Q}$-vector diagnosis and vorticity budget analysis indicate that the upper-level positive vorticity advection associated with the RWB is an important factor dynamically inducing ascent and reinforcing convection over the subtropical WNP, which in turn excites the subsequent PJ pattern. Classification of the cases by RWB strength indicates that the stronger RWB is significantly related to the stronger preceding SWP and subsequent enhanced PJ pattern, and vice versa. A partial correlation analysis of all the cases quantitatively shows the greater contribution of the upper-level positive vorticity advection over the subtropical WNP to the enhanced convection in this area and the formation of the PJ pattern, compared to that of the anomalous warm sea surface temperature condition. These results show that the SWP along the Asian jet can excite the PJ pattern, through the RWB east of Japan and the consequent intrusion of the high PV toward the subtropical WNP.
\end{abstract}

Keywords teleconnection; wave breaking; Asian monsoon; Tibetan high; Pacific high

Citation Takemura, K., and H. Mukougawa, 2020: Dynamical relationship between quasi-stationary Rossby wave propagation along the Asian jet and Pacific-Japan pattern in boreal summer. J. Meteor. Soc. Japan, 98, 169-187, doi:10.2151/jmsj.2020-010.

Corresponding author: Kazuto Takemura, Graduate School of Science, Kyoto University, Kitashirakawa Oiwake-cho, Sakyo, Kyoto 606-8502, Japan

E-mail: takemura.kazuto@kugi.kyoto-u.ac.jp

J-stage Advance Published Date: 1 December 2019

\section{Introduction}

Enhanced and persistent extension of the North Pacific Subtropical High (NPSH) is tightly linked to an anomalous summer climate over Japan, such as significantly hot conditions (e.g., Lu and Dong 2001; Shimpo et al. 2019) and, in some cases, torrential rain- 
fall events because of the prevailing moisture inflow along the western fringe of the NPSH (e.g., Rodwell and Hoskins 2001; Sekizawa et al. 2019; Takemura et al. 2019). Enomoto et al. (2003) showed the existence of an equivalent barotropic anticyclone over Ogasawara Island that covers Japan during the postBaiu season of the boreal summer, and referred it to as the Bonin high. Previous studies showed that the variability of the Bonin high is associated with two teleconnection patterns: the Silk Road (Enomoto et al. 2003; Enomoto 2004) and Pacific-Japan (PJ) patterns (Nitta 1987; Kosaka and Nakamura 2006). Lu et al. (2002) showed the existence of a wave train trapped along the westerly jet from North Africa to Eurasia during summer. Enomoto et al. (2003) referred to the wave train over Eurasia as "the Silk Road pattern", which features a quasi-stationary Rossby wave propagation (SWP) along the Asian jet, inducing enhancement of the Bonin High through Rossby wave breaking (RWB) over the western North Pacific (WNP). The WNP climatologically corresponds to the Asian jet exit region, and it is well known that the SWP along the Asian jet can induce the RWB in this area (e.g., Postel and Hitchman 1999, 2001; Abatzoglou and Magnusdottir 2006; Hitchman and Huesmann 2007; Homeyer and Bowman 2013). Takemura et al. (2017) showed that the equatorward intrusion of the high potential vorticity (PV) associated with the RWB results in dynamic ascent and promotes enhanced convection and the typhoon formation over the subtropical WNP. Horinouchi (2014) and Funatsu and Waugh (2008) also suggested using the $\boldsymbol{Q}$-vector diagnosis that the enhanced upwelling and consequent active convection is dynamically induced because of the upper-level high PV over East Asia and the WNP. Moreover, it is well known that the equatorward-propagating Rossby wave over the North Pacific contributes to enhanced convection and synoptic-scale disturbances including typhoons and hurricanes over the tropical Pacific (Matthews and Kiladis 2000; Tam and $\mathrm{Li}$ 2006). These previous studies suggest influence of extratropical atmospheric variability on the tropical atmosphere through the RWB. Nitta (1987) found the PJ pattern, which is a lower-level teleconnection pattern, is characterized by a meridional seesaw between the enhanced (suppressed) convection over the Philippines and anticyclonic (cyclonic) circulation anomalies over Japan, respectively. The PJ pattern with enhanced convection over the Philippines corresponds to the enhancement of the Bonin high associated with the extension of the NPSH toward mainland Japan (Wakabayashi and Kawamura 2004); it results in hot summer conditions in this area (e.g., Kawamura et al. 1998, 2001). Although the PJ pattern can be affected by the RWB and the consequent enhanced convection over the subtropical WNP as shown by the aforementioned previous studies, a rigorous connection between the RWB and PJ pattern has not been shown.

Kosaka et al. (2009) and Kosaka and Nakamura (2010) showed the coexistence of the Silk Road and PJ patterns, based on a statistical analysis using a monthly-mean reanalysis dataset. However, a process linking these two teleconnection patterns was not clarified by these previous studies. Japan Meteorological Agency (2013: JMA) performed a case study of the boreal summer of 2012, and showed an influence of the SWP on the formation of the PJ pattern through the RWB east of Japan at a timescale of approximately 1 week. This case study indicates that the RWB near the jet exit region is an important factor linking the SWP along the Asian jet and PJ pattern. The following statistical analysis based on similar cases was needed to show the significance of the process linking these two patterns. It was highly expected that a statistical analysis based on not only monthly but also sub-monthly timescales could clearly describe the primary importance of the RWB.

The present study shows a new possible process that the SWP along the Asian jet and the subsequent RWB near the jet exit region can excite the PJ pattern, based on a lag composite analysis using a daily reanalysis dataset. This line of investigation is important to promote our understanding of the major factors causing the anomalous summer climate over Asia, and to make further progress in forecasting the interaction between extratropical and tropical variabilities. It is also expected that this study will contribute to reduce the socio-economic impacts of the increased and unprecedented heat waves resulting from ongoing global warming (Imada et al. 2019).

The reminder of the present paper is organized as follows. Section 2 describes the dataset and analytical methods. In Section 3, the climatology over a region from Asia to the North Pacific is described to provide an overview of the circulation characteristics during the boreal summer Asian monsoon season. In Section 4 , results of the lag composite analysis for all the extracted RWB cases and the cases classified by RWB strength are provided to show the significance of the process linking the SWP along the Asian jet and the PJ pattern through the RWB. In Section 5, using a quasigeostrophic diagnosis, we assess the contribution of the upper-level positive vorticity advection associated with the RWB to the enhanced convection over the 
subtropical WNP. The results of a partial correlation analysis are described in Section 6 to show the relative importance of the upper-level positive vorticity advection and anomalous sea surface temperature (SST) to the enhancement of convection and the PJ pattern. Section 7 provides the major findings of the study.

\section{Data and methods}

The data used in this study are those from daily mean datasets of the Japanese 55-year reanalysis (JRA-55) for June-September (JJAS) during the 61year period from 1958 to 2018, with a horizontal resolution of $1.25^{\circ}$ and 37 pressure levels from 1000 to $1 \mathrm{hPa}$ (Kobayashi et al. 2015). We also used the daily mean dataset of COBE-SST (Ishii et al. 2005) for June-August during the 61-year period, with a resolution of $1^{\circ}$, to analyze SST. Here, the anomaly is defined as a departure from the climatology, which is obtained as the 60-day low-pass (Lanczos; Duchon 1979) filtered 30-year daily averages from 1981 to 2010. To extract low-frequency components including the quasi-stationary Rossby wave, a 5-day-running mean is applied to the daily data. We applied a horizontal smoothing filter to relative vorticity fields using a triangular truncation retaining $\mathrm{N}=24$ wavenumbers (T24) to exclude the disturbances at a scale smaller than synoptic eddies.

The propagation of quasi-stationary Rossby wave packets is analyzed using the wave activity flux (WAF) defined by Takaya and Nakamura (2001). The horizontal WAF is defined as follows:

$$
\boldsymbol{W}=\frac{1}{2|\boldsymbol{U}|}\left(\begin{array}{l}
\bar{u}\left(\psi_{x}^{\prime 2}-\psi^{\prime} \psi_{x x}^{\prime}\right)+\bar{v}\left(\psi_{x}^{\prime} \psi_{y}^{\prime}-\psi^{\prime} \psi_{x y}^{\prime}\right) \\
\bar{u}\left(\psi_{x}^{\prime} \psi_{y}^{\prime}-\psi^{\prime} \psi_{x y}^{\prime}\right)+\bar{v}\left(\psi_{y}^{\prime 2}-\psi^{\prime} \psi_{y y}^{\prime}\right)
\end{array}\right),
$$

where $u$ is the zonal wind, $v$ is the meridional wind, $\boldsymbol{U}$ is the climatological horizontal wind vector, and $\psi$ is the geostrophic stream function at a reference latitude of $\phi_{0}=40^{\circ} \mathrm{N}$. The overbars (primes) denote the basic states (perturbations), defined as the climatology (anomaly). The subscripts $x$ and $y$ denote the partial derivatives with respect to longitude and latitude, respectively.

To assess the waveguide of the quasi-stationary Rossby wave packets, the meridional gradient of the climatological absolute vorticity, which is referred to as effective $\beta$ (Hoskins and Ambrizzi 1993), is calculated from the climatological zonal wind. The effective $\beta\left(\beta^{*}\right)$ is defined as follows:

$$
\beta^{*} \equiv \beta-\frac{\partial^{2} \bar{u}}{\partial y^{2}}
$$

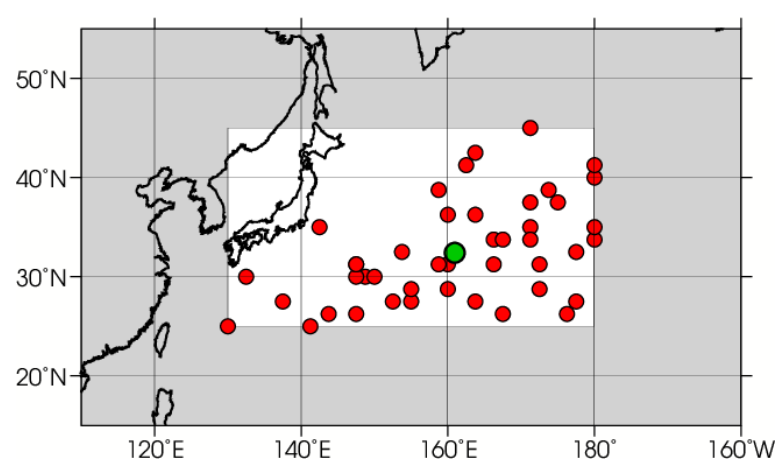

Fig. 1. Central positions of the extracted 44 RWB cases (red-colored circle) and their average position (green-colored circle) at $32.4^{\circ} \mathrm{N}, 160.9^{\circ} \mathrm{E}$. The white rectangle denotes the region $\left(25-45^{\circ} \mathrm{N}\right.$, $130^{\circ} \mathrm{E}-180^{\circ}$ ) used to extract the RWB cases.

where $\beta$ is the meridional gradient of the latitudedependent planetary vorticity.

To identify the RWB cases east of Japan, we used a dynamical blocking index (Pelly and Hoskins 2003) based on the meridional distribution of potential temperature $(\theta)$ on the dynamical tropopause defined by two potential vorticity units (PVUs). The blocking index $(B$; unit: $\mathrm{K})$ is expressed as follows:

$$
B=\frac{1}{\Delta \lambda} \int_{-\Delta \lambda / 2}^{\Delta \lambda / 2}\left\{\frac{2}{\Delta \phi}\left(\int_{\phi_{0}}^{\phi_{0}+\Delta \phi / 2} \theta d \phi-\int_{\phi_{0}-\Delta \phi / 2}^{\phi_{0}} \theta d \phi\right)\right\} d \lambda,
$$

where $\lambda$ is the longitude, $\Delta \lambda$ is the width of zonal average, $\phi$ is the latitude, $\Delta \phi$ is the typical meridional scale of the wave breaking, and $\phi_{0}$ is the central latitude. We defined $\Delta \lambda$ as $5^{\circ}$ and $\Delta \phi$ as $30^{\circ}$, respectively, according to Pelly and Hoskins (2003). $B$ has a positive value when there is high $\theta$ to the north and low $\theta$ to the south. An RWB event is detected when $B$ is positive for at least four consecutive days for the period July-August from 1958 to 2018. Note that the RWB event with a smaller $B$ is excluded when two peaks of $B$ are detected within a period of 15 days to prevent effects of overlap during the period of two RWB events on the lag composite analysis. To conduct the lag composite analysis, we extracted the 44 strongest RWB events (red-colored circle in Fig. 1) that occurred over the region from Japan to its east $\left(25-45^{\circ} \mathrm{N}, 130^{\circ} \mathrm{E}-180^{\circ}\right.$, white rectangle in Fig. 1) with a maximum $\mathrm{B}$ higher than a threshold of $+15 \mathrm{~K}$ (red-colored circle in Fig. 1). The region from which the RWB cases were extracted is defined according to 
the following two points: (1) the maximum frequency of the RWB is climatologically seen over the WNP (Abatzoglou and Magnusdottir 2006; Bowley et al. 2019), and (2) the RWB over the region can geographically affect the enhanced convection to its south and the PJ pattern over the WNP. Similar lag composite analysis results are shown even if the region and the threshold $B$ are altered, although the amplitude and phase of the anomalies slightly weaken. The case of the boreal summer of 2012 investigated by JMA (2013) is also included in the extracted cases. A central date of the RWB case was defined as "day 0" in the lag composite analysis.

To sharpen the composited signatures, the entire field was horizontally shifted before the composite analysis in such a manner that the central positions of the RWBs at day 0 coincide with the reference point, which was defined as the averaged position of the 44 RWB cases on day 0 (green-colored circle in Fig. 1).

To assess the dynamical relationship between the equatorward intrusion of high PV air and enhanced convection, vertical motion induced under the quasi-geostrophic balance was diagnosed using $\boldsymbol{Q}$-vectors (e.g., Hoskins et al. 1978; Holton 1992), defined in Eq. (4b), which was incorporated into the conventional diagnostic equation for the vertical motion (i.e., the $\omega$ equation) as follows:

$$
\begin{aligned}
&\left(\nabla^{2}+\frac{f_{0}^{2}}{\sigma} \frac{\partial^{2}}{\partial p^{2}}\right) \omega \cong \frac{f_{0}}{\sigma} \frac{\partial}{\partial p}\left[\boldsymbol{v}_{g} \cdot \nabla\left(\frac{1}{f_{0}} \nabla^{2} \Phi+f\right)\right] \\
&+\frac{1}{\sigma} \nabla^{2}\left[\boldsymbol{v}_{g} \cdot \nabla\left(-\frac{\partial \Phi}{\partial p}\right)\right] \\
& \cong-\frac{2}{\sigma} \nabla \cdot \boldsymbol{Q}+\frac{f_{0}}{\sigma} \beta \frac{\partial v_{g}}{\partial p}, \\
& \boldsymbol{Q} \equiv\left(-\frac{R}{p} \frac{\partial \boldsymbol{v}_{g}}{\partial x} \cdot \nabla T,-\frac{R}{p} \frac{\partial \boldsymbol{v}_{g}}{\partial y} \cdot \nabla T\right)
\end{aligned}
$$

where $\omega$ is the vertical $p$-velocity, $f_{0}$ is the reference Coliolis parameter at the latitude of $\phi_{0}, f$ is the Coliolis parameter, $\boldsymbol{v}_{g}=\left(u_{g}, v_{g}\right)$ is the geostrophic horizontal wind vector, $\Phi$ is the geopotential, and $T$ is the temperature, respectively. $\sigma \equiv R T_{0} p^{-1} d \ln \theta_{0} / d p$ is the static stability, with the gas constant $R$ and the basic-state potential temperature $\theta_{0}$, derived from the area-averaged temperature $T_{0}$ north of $20^{\circ} \mathrm{N}$. Equation (4a-1) indicates that the vertical motion is balanced with the vertical derivatives of vorticity advection (the first term of the RHS) and thermal advection (the second term of the RHS). Convergence and divergence of the $\boldsymbol{Q}$-vectors, which are proportional to the first term of Eq. (4a-2), correspond to dynamically induced ascent and descent, respectively. Although a sum of the two terms of Eq. (4a-2) approximately expresses the total effect of the vorticity and thermal advection (RHS of Eq. 4a-1), the composite of the first term of Eq. (4a-2) shows a similar pattern to the total term of the equation (not shown), implying the validity of the $\boldsymbol{Q}$-vector diagnosis in the present study. For adiabatic flow, the vertical motion can be solely represented by the $\boldsymbol{Q}$-vector patterns. The $\boldsymbol{Q}$-vectors can be calculated on a given isobaric surface using geopotential height and temperature. Furthermore, we conducted a simple vorticity budget analysis to show the relative importance of the upper-level vorticity advection associated with the RWB to the enhanced ascent, compared to that of the thermal advection. The anomalous absolute vorticity advection by a horizontal wind is expressed as follows:

$$
\left[\frac{\partial \xi^{\prime}}{\partial t}\right]_{a d v} \cong-\boldsymbol{v}^{\prime} \cdot \nabla(\bar{\zeta}+f)-\overline{\boldsymbol{v}} \cdot \nabla \zeta^{\prime},
$$

where $\xi$ is the absolute vorticity, $\boldsymbol{v}$ is the horizontal wind vector, and $\zeta$ is the relative vorticity, respectively. The overbars and primes are defined as in Eq. (1). The first and second terms of RHS in Eq. (5) indicate the contributions of anomalous and climatological horizontal wind to the absolute vorticity tendency, respectively.

\section{Climatological characteristics over the Asia-Pacific region}

Figure 2 shows the climatology of 200- and 850$\mathrm{hPa}$ height, WAF and effective $\beta$, and $350-\mathrm{K}$ isentropic $\mathrm{PV}$ averaged over the period July-August. The height field at $200 \mathrm{hPa}$ shows an amplified planetary-scale anticyclone over southern Eurasia, corresponding to the enhancement of the Tibetan High (contour in Fig. 2a). The formation of the upper-level anticyclone is a result of the tropical active convection associated with the Asian summer monsoon (shading in Fig. 2c). The Asian jet is clearly seen along the latitudinal band of $30-50^{\circ} \mathrm{N}$ north of the Tibetan High and plays a crucial role as the quasi-stationary Rossby waveguide (shading in Fig. 2a). The propagating wave energy along the Asian jet can break near the jet exit region east of Japan, which is favorable for RWB occurrence. This result is consistent with that of Postel and Hitchman (1999), who examined the RWB climatology over the subtropical tropopause during summer. The PV at 350 $\mathrm{K}$ shows an equatorward extension of the high $\mathrm{PV}$ near the dateline (Fig. 2b) associated with the RWB, 
(a) Z200 \& WAF clim.

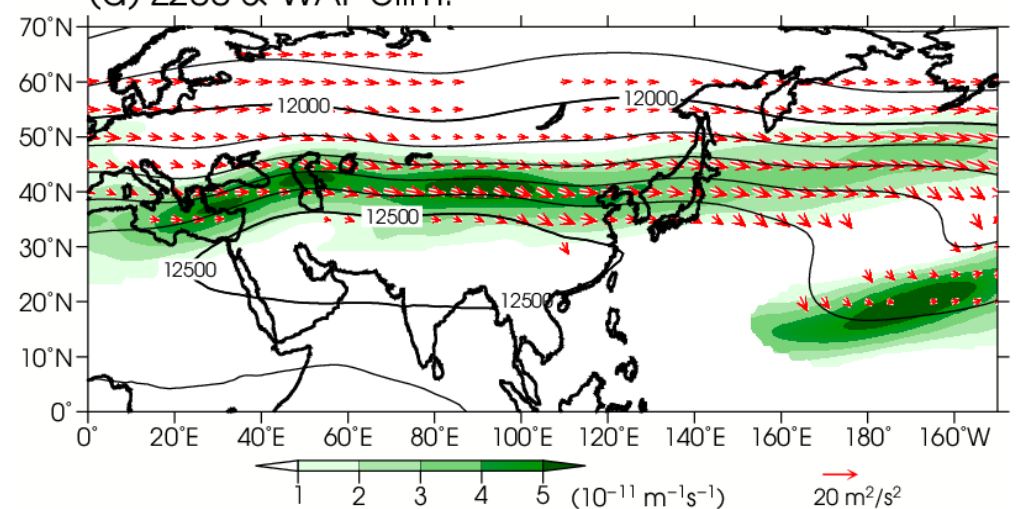

(b) $350 \mathrm{~K}$ PV clim.

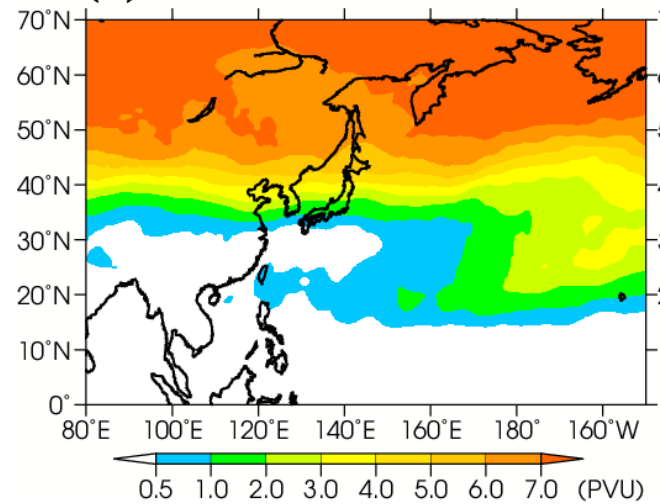

(c) Z850 \& WAF clim.

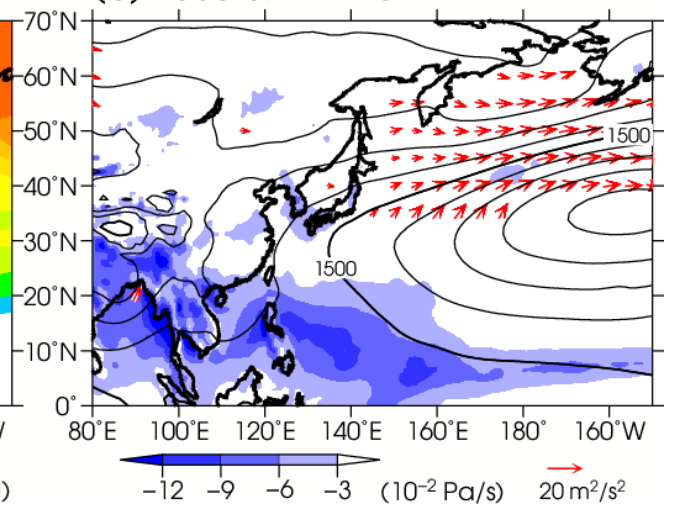

Fig. 2. Climatological (a) 200-hPa height (contour interval: $100 \mathrm{~m}$ ), meridional gradient of absolute vorticity (shading; unit: $10^{-11} \mathrm{~m}^{-1} \mathrm{~s}^{-1}$ ), (b) 350-K potential vorticity, and (c) $850-\mathrm{hPa}$ height (contour interval: $20 \mathrm{~m}$ ) and 500-hPa vertical $p$-velocity (shading; unit: $10^{-2} \mathrm{~Pa} \mathrm{~s}^{-1}$ ) averaged for July-August. Red vectors indicate the time average of daily WAF (unit: $\mathrm{m}^{2} \mathrm{~s}^{-2}$ ) derived from the 5-day running mean over the climatological period.

contributing to the formation of the climatological mid-Pacific trough (contour in Fig. 2a).

In the lower troposphere, a low-pressure system is seen over southern Eurasia associated with the active Asian summer monsoon (Fig. 2c), and showing a baroclinic structure with an upper-level anticyclone (Fig. 2a). A high-pressure system (i.e., the NPSH) and its westward extension is clearly seen over the North Pacific associated with the active convection over a region from the Philippines to its east. The enhanced convection over the Philippines and the positive height anomalies over Japan, which are associated with the PJ pattern, correspond to the enhanced extension of the NPSH toward mainland Japan (Wakabayashi and Kawamura 2004).

\section{Lag composite analysis of the 44 RWB cases}

Figure 3 shows the composite of the upper- and lower-tropospheric relative vorticity anomalies and
$350-\mathrm{K}$ PV on days $-7,-2,0,+2,+4$ for the 44 RWB cases. The SWP along the Asian jet is enhanced beginning on day -7 (Fig. 3a) and attains its peak on day -2 (Fig. 3d). The wave energy accumulates near the jet exit region and contributes to RWB occurrence, accompanied by an amplified anomalous anticyclone east of Japan and a deepened trough south (Figs. 3d, g). The horizontal distribution of the 350-K PV shows an "inverse-S" shaped overturning associated with the RWB from day -2 to day 0 , with a northeastward intrusion of low PV toward the sea east of Japan and a southwestward intrusion of high PV toward the subtropical WNP, respectively (Figs. 3e, h). All of the 44 RWB cases are categorized as an anticyclonic (i.e., inverse-S) type because of the anticyclonic wind shear south of the jet core (not shown). This result is consistent with that of Bowley et al. (2019), which indicated much a higher frequency of anticyclonic RWBs compared to the cyclonic type over the WNP 
(a) $200 \mathrm{hPa}($ day -7$)$

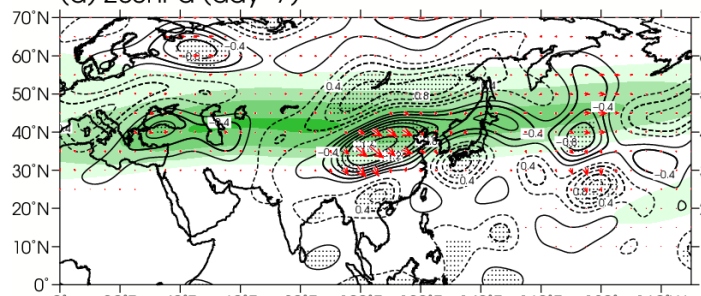

(d) $200 \mathrm{hPa}($ day-2)

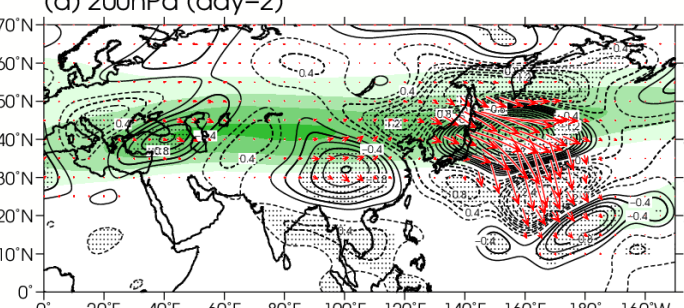

(g) $200 \mathrm{hPa}$ (dayo)

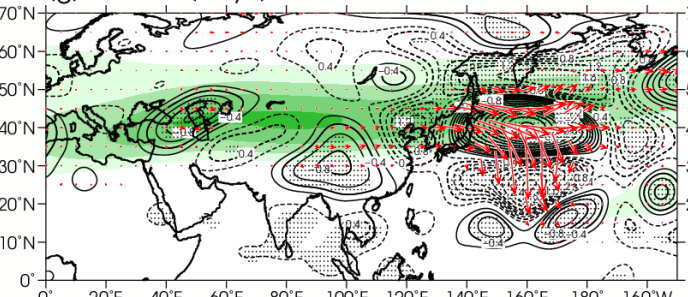

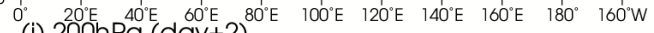

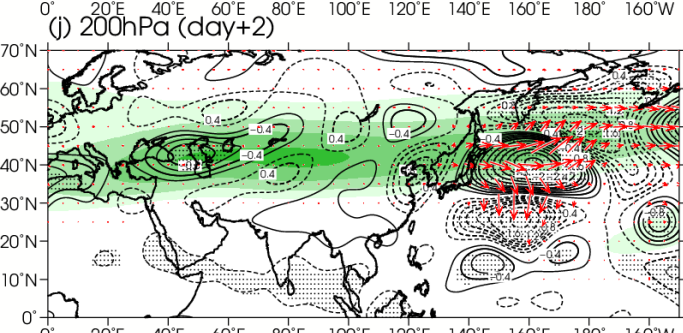

(m) $200 h P a(d a y+4)$

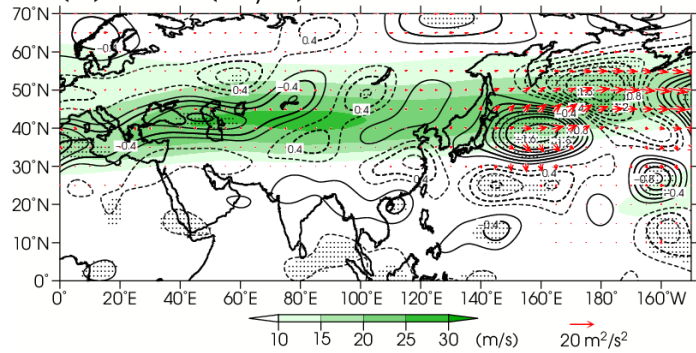

(b) $350 \mathrm{~K}$ (day-7)

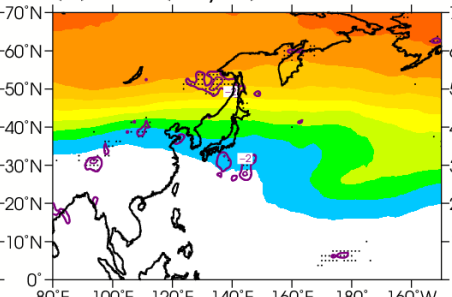

${ }^{80^{\circ}} \mathrm{E}$ (e) $350^{100^{\circ}} \mathrm{K}$ (day-2)

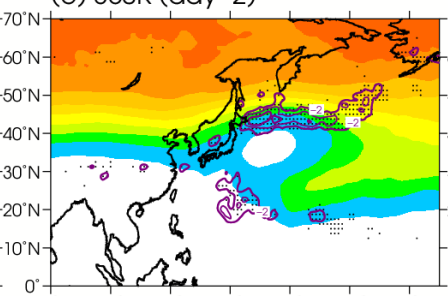

$\left.80^{\circ} \mathrm{E}\right) 100^{\circ} \mathrm{E} \mathrm{K}^{120^{\circ} \mathrm{E} \quad 10^{\circ} \mathrm{O}}$

(c) $850 \mathrm{hPa}(\mathrm{day}-7)$

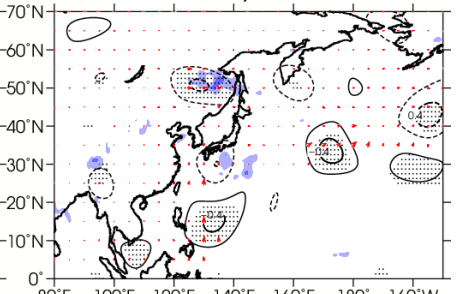

(f) $8500^{\circ} \mathrm{hPa}(\mathrm{day}-2)$
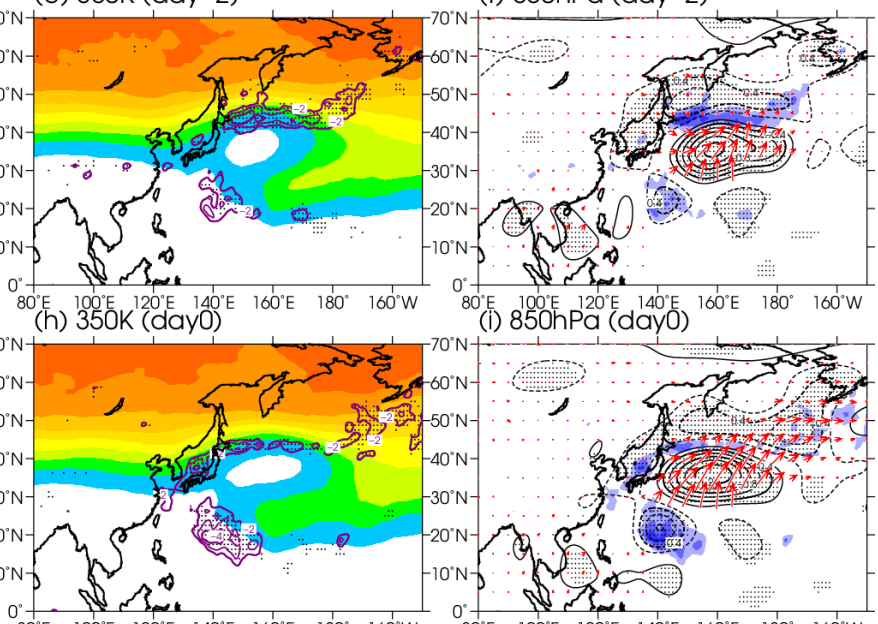

$80^{\circ} \mathrm{E}{ }^{100^{\circ}} \mathrm{E} / 120^{\circ} \mathrm{E}\left(140^{\circ} \mathrm{E}\right)$
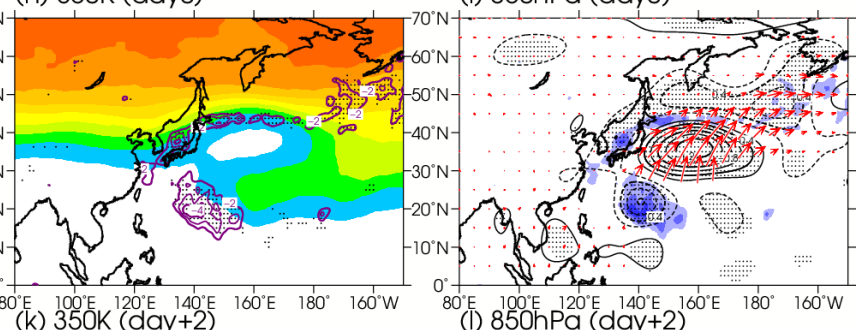

$\left.\left.80^{\circ} \mathrm{E}\right) 100^{\circ} \mathrm{K} K \mathrm{~K}^{120^{\circ} \mathrm{E}} 140^{\circ} \mathrm{E}\right)$
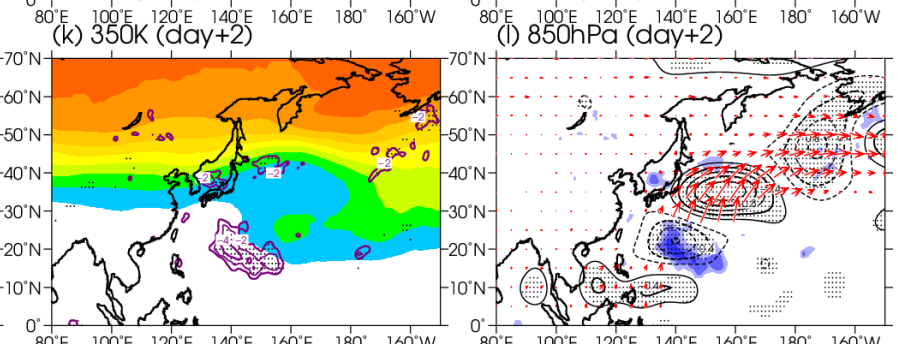

${ }^{80^{\circ} \mathrm{E}} 100^{\circ} \mathrm{E} \mathrm{K}^{120^{\circ} \mathrm{E}} 140^{\circ} \mathrm{E}$

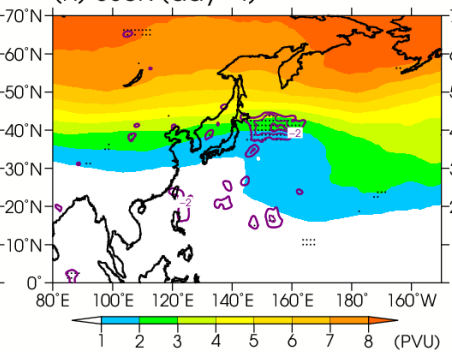

$\left.80^{\circ} \mathrm{E}\right) 100^{\circ} \mathrm{E} \mathrm{h}^{120^{\circ} \mathrm{E}} 140^{\circ} \mathrm{E}$
(O) $850 \mathrm{~h}^{160}$

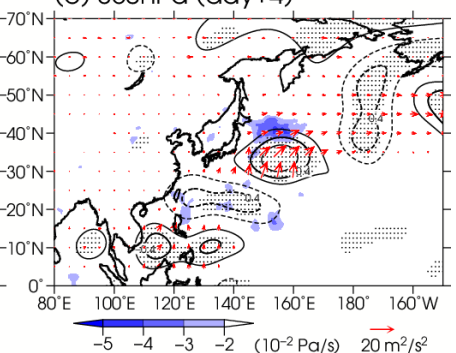

Fig. 3. Composite of (left) $200-\mathrm{hPa}$ anomalous relative vorticity (contour; unit: $10^{-5} \mathrm{~s}^{-1}$ ), climatological zonal wind (shading; unit: $\mathrm{m} \mathrm{s}^{-1}$ ), (middle) 350-K potential vorticity (shading; unit: PVU), 500-hPa anomalous negative vertical $p$-velocity (purple contour; unit: $10^{-2} \mathrm{~Pa} \mathrm{~s}^{-1}$ ), (right) $850-\mathrm{hPa}$ anomalous relative vorticity (contour), and 500$\mathrm{hPa}$ anomalous vertical $p$-velocity (shading) for the $44 \mathrm{RWB}$ cases. Solid and dashed contours on the left and right panels denote negative and positive vorticity anomalies, respectively. Red vectors indicate the WAF (unit: $\mathrm{m}^{2} \mathrm{~s}^{-2}$ ). Black dots indicate statistical significance at a $95 \%$ level of the anomalous (left, right) relative vorticity and (middle) 500-hPa vertical p-velocity. (a, b, c) day $-7,(\mathrm{~d}, \mathrm{e}, \mathrm{f})$ day $-2,(\mathrm{~g}, \mathrm{~h}, \mathrm{i})$ day $0,(\mathrm{j}, \mathrm{k}, \mathrm{l})$ day +2 , and $(\mathrm{m}, \mathrm{n}, \mathrm{o})$ day +4 . 


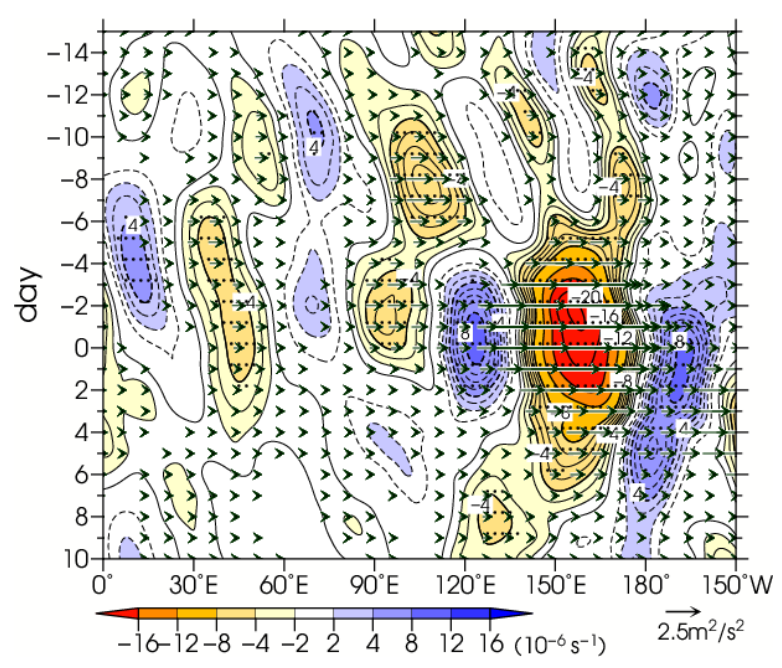

Fig. 4. Hovmöller diagram of composited 5-day running mean $200-\mathrm{hPa}$ relative vorticity anomalies at intervals of $1 \times 10^{-6} \mathrm{~s}^{-1}$ and the zonal component of WAF (vectors; unit: $\mathrm{m}^{2} \mathrm{~s}^{-2}$ ) averaged between $30^{\circ} \mathrm{N}$ and $50^{\circ} \mathrm{N}$ from day -15 to day +10 . Solid and dashed contours denote negative and positive vorticity anomalies, respectively. Black dots indicate statistical significance at a $95 \%$ level of the anomalous 200-hPa relative vorticity.

during summer. The equatorward intrusion of the upper-level high PV corresponds to the enhancement of the climatological mid-Pacific trough (Fig. 2a). The southwestward intrusion of the high PV is accompanied by enhanced convection east of the Philippines (Figs. 3e, h, k). In the lower troposphere, southwestnortheast-oriented dipole vorticity anomalies arise on day -2 that are associated with the RWB occurrence (Figs. 3e, f), and are enhanced until day +2 (Figs. 3i, 1). The dipole anomalies are accompanied by cyclonic circulation anomalies northeast of the Philippines and anticyclonic circulation anomalies east of mainland Japan, corresponding to the PJ pattern associated with the enhanced convection east of the Philippines. An enhancement of the anticyclonic circulation anomalies in the lower troposphere occurs prior to the enhancement of those that are cyclonic on day -2 (Fig. 3f), exhibiting the equivalent barotropic structure with an amplified anomalous anticyclone in the upper troposphere (Fig. 3d). This is consistent with the formation mechanism of the Bonin high (Enomoto et al. 2003), and is different from the well known formation mechanism of the PJ pattern as clearly seen from day 0 to day +2 (Figs. 3i, 1). The SWP along the Asian jet becomes obscure on day +2 (Fig. $3 j$ ). On day +4 , the

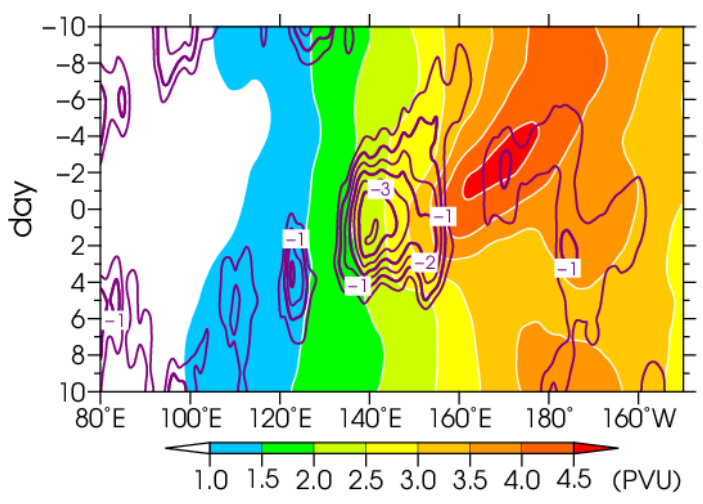

Fig. 5. Same as Fig. 4, but for composite of the 5-day running mean $360-\mathrm{K}$ isentropic potential vorticity (shading; unit: PVU) averaged between $20^{\circ} \mathrm{N}$ and $30^{\circ} \mathrm{N}$ and $500-\mathrm{hPa}$ negative vertical $p$-velocity anomalies (purple contour) averaged between $15^{\circ} \mathrm{N}$ and $25^{\circ} \mathrm{N}$ at an interval of $0.5 \times$ $10^{-2} \mathrm{~Pa} \mathrm{~s}^{-1}$. The $360-\mathrm{K}$ isentropic level corresponds to the subtropical tropopause.

RWB east of Japan terminates with the elimination of the PV overturning in the upper troposphere (Fig. 3n); consequently, the active convection and PJ pattern also weaken and dissipate (Fig. 3o).

Figure 4 shows the longitude-time cross section of $200-\mathrm{hPa}$ anomalous relative vorticity anomalies and WAF along the Asian jet from day -15 to day +10 . The SWP along the Asian jet is clearly seen from day -5 to day 0 (Figs. $3 \mathrm{~d}, \mathrm{~g}$ ), contributing to the enhancement and persistence of the large-amplitude anomalous anticyclone around $160^{\circ} \mathrm{E}$. Another SWP is also seen from day -12 to day -7 , although its amplitude is weaker than that of the SWP seen beginning on day -5 , contributing to an enhancement of the anomalous anticyclone around $110^{\circ} \mathrm{E}$. Thus, the RWB east of Japan is mainly caused by the SWP seen beginning on day -5 .

The longitude-time cross section of $360-\mathrm{K}$ PV averaged between $20^{\circ} \mathrm{N}$ and $30^{\circ} \mathrm{N}$ and the $500-\mathrm{hPa}$ anomalous vertical $p$-velocity averaged between $15^{\circ} \mathrm{N}$ and $25^{\circ} \mathrm{N}$ are shown in Fig. 5 to confirm the relationship between the southwestward intrusion of the upper-level high PV and the enhanced convection east of the Philippines. The enhanced convection is clearly seen ahead of the upper-level westward-moving high $\mathrm{PV}$ from the dateline to $150^{\circ} \mathrm{E}$ from day -4 to day 0 . These results are consistent with those of Sato et al. (2005) and Takemura et al. (2017): The former suggested that the high PV associated with upper cold 


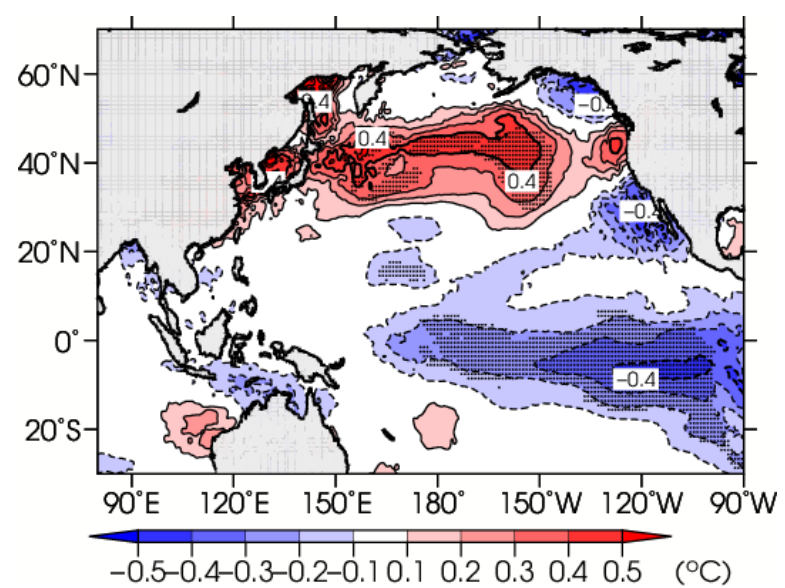

Fig. 6. Composite of anomalous SST (unit: ${ }^{\circ} \mathrm{C}$ ) averaged from day -15 to day -6 . Black dots indicate statistical significance at a $95 \%$ level of the anomalous SST.

lows migrating westward from the mid-Pacific trough contributes to the enhancement of convective activities around Marcus Island while the latter showed that the southward intrusion of the upper-level high PV promotes dynamic upward motion and enhanced convection over the subtropical WNP. The enhanced convective activity attains its maximum around $140^{\circ} \mathrm{E}$ from day -1 to day +3 following the westward migration of the upper-level high PV, indicating the contribution of the high PV intrusion to the formation of the PJ pattern through enhanced convection (Figs. $3 \mathrm{~h}$, i). The PJ pattern implies the extension of the NPSH toward mainland Japan and contributes to hot summer conditions and, in some cases, torrential rainfall, as described in Section 1. Figure 6 shows a composite of anomalous SSTs averaged during the period from day -15 to day -6 when the SST is not affected by evaporative cooling resulting from an intensified surface wind (i.e., the wind-evaporation-SST (WES) feedback; Xie and Philander 1994) associated with the enhanced convection east of the Philippines. There is no significant anomalous warm SST over the subtropical WNP that can contribute to the convective activity before the onset of the enhanced convection in this area and the PJ pattern. Notably, the significant anomalous cold SST is dominant over the equatorial central to eastern Pacific, indicating that La Niña conditions are favorable for RWB cases east of Japan. A detailed mechanism for the influence of the El Niño Southern Oscillation on the RWB near the Asian jet exit region should be examined from the perspective (a)

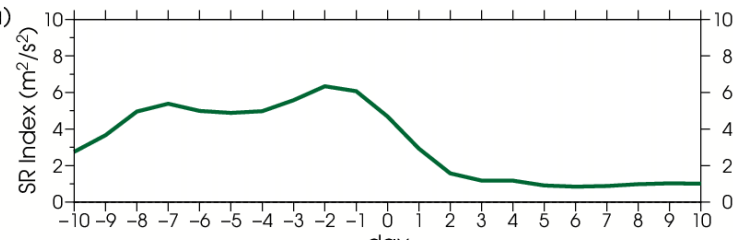

(b)

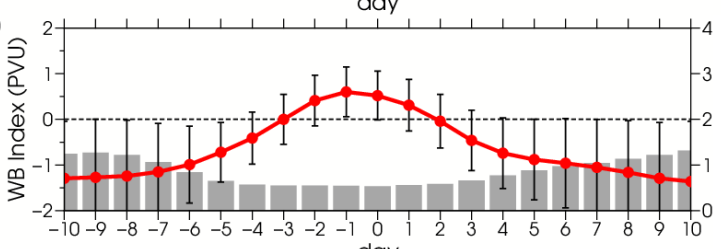

(c)

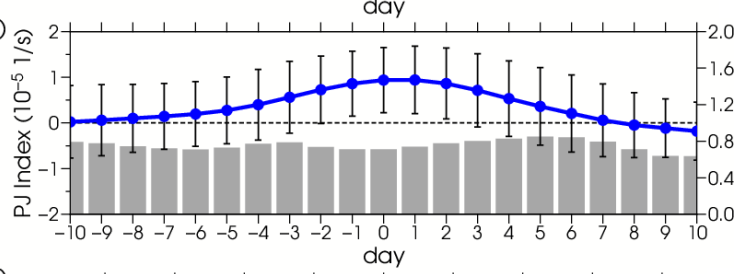

(d)

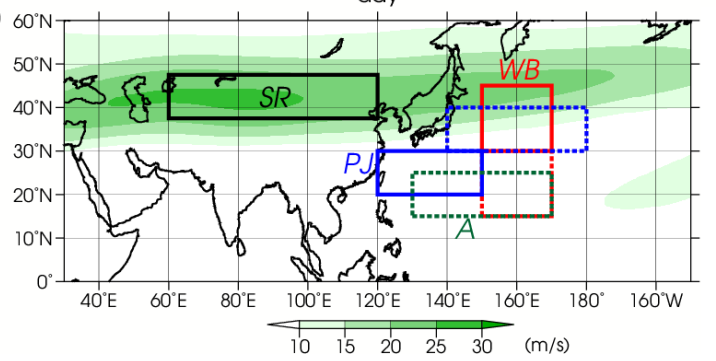

Fig. 7. Five-day running mean timeseries of three indices from day -10 to day +10 . (a) SR index (unit: $\mathrm{m}^{2} \mathrm{~s}^{-2}$ ), (b) WB index (unit: PVU), (c) PJ index (unit: $10^{-5} \mathrm{~s}^{-1}$ ) on the left axis, and (d) defined region of the three indices labeled SR, WB, and PJ. Error bars and gray bars (right axes) in (b) and (c) denote the standard deviation of the indices. Green shading in (d) indicates the $200-\mathrm{hPa}$ climatological zonal wind (unit: $\mathrm{m} \mathrm{s}^{-1}$ ) on day 0 . See text for the definition of the three indices. Dashed green rectangle labeled by " $A$ " denotes the region used to calculate areal averages defined in Sections 5 and 6.

of inter-annual variability in future studies.

Here, we define three indices representing the SWP strength along the Asian jet, RWB, and PJ pattern. The first index is the Silk Road (SR) index, defined as the 200-hPa eddy (i.e., zonal wave numbers $k \geq 3$ ) kinetic energy averaged longitudinally between $60^{\circ} \mathrm{E}$ and $120^{\circ} \mathrm{E}$ and latitudinally between $-5^{\circ}$ and $+5^{\circ}$ from the 200-hPa climatological zonal wind (green shading in Fig. 7d) maxima at each longitude (black rectangle in Fig. 7d), following the procedure of Enomoto (2004). 
The decomposition of the eddy $(k \geq 3)$ component can be separated from the variability of the Tibetan High itself (i.e., $k<3$ ), and the longitudinal range from $60^{\circ} \mathrm{E}$ and $120^{\circ} \mathrm{E}$ is away from the climatological wave source and sink (Enomoto 2004). The large SR index value thus corresponds to the increased northsouth meandering of the Asian jet, indicating the enhanced SWP. The second is the wave breaking (WB) index, defined as the difference in the areal averages of $350-\mathrm{K}$ PV between $\left[15-30^{\circ} \mathrm{N}, 150-170^{\circ} \mathrm{E}\right]$ (red dashed rectangle in Fig. $7 \mathrm{~d}$ ) and $\left[30-45^{\circ} \mathrm{N}, 150-\right.$ $\left.170^{\circ} \mathrm{E}\right]$ (red solid rectangle in Fig. $7 \mathrm{~d}$ ). A positive WB index value indicates RWB occurrence with reversal of the meridional gradient of the PV east of Japan. The third is the PJ index, defined as the difference in the $850-\mathrm{hPa}$ anomalous relative vorticity between $\left[20-30^{\circ} \mathrm{N}, 120-150^{\circ} \mathrm{E}\right]$ (blue solid rectangle in Fig. $7 \mathrm{~d}$ ) and $\left[30-40^{\circ} \mathrm{N}, 140-180^{\circ} \mathrm{E}\right]$ (blue dashed rectangle in Fig. 7d). The two regions are defined according to the dipole vorticity anomalies in the lower troposphere seen from day 0 to day +4 (Figs. $3 i, 1$, o). A positive PJ index value corresponds to the enhancement of cyclonic and anticyclonic circulation anomalies near the Philippines and east of Japan, respectively. Figures $7 \mathrm{a}, 7 \mathrm{~b}$, and $7 \mathrm{c}$ show time variations in the SR, WB, and PJ indices from day -10 to day +10 , respectively. An increased and large SR index is seen from day -7 to day -2 (Fig. 7a), corresponding to the enhanced SWP along the Asian jet as shown in Fig. 4. Thereafter, the SR index rapidly decreases and has small values after day +2 , corresponding to the weakening of the SWP (Figs. 3j, m). The WB index subsequently increases until day -1 , associated with RWB occurrence east of Japan resulting from the enhanced SWP (Fig. 7b), followed by a peak in the PJ index on day +1 (Fig. 7c). These time variations show that the enhancement of the SWP along the Asian jet, consequential RWB, and subsequent formation of the PJ pattern can occur within a timescale of approximately 1 week.

These results indicate a possible process in which the SWP along the Asian jet can excite the PJ pattern, through the RWB-related southwestward intrusion of the upper-level high PV toward the subtropical WNP and the subsequent enhanced convection ahead of the upper-level westward-moving high PV.

To assess the relationship of anomalous circulation over the Asia-Pacific region to the RWB strength in each case, we conducted a composite analysis for the cases classified by the WB index. Here, "Case+" and "Case-" are defined as cases in which the WB index on day 0 exceeded +1 and was less than -1 standard deviations of the composite, respectively. Figures 8 and 9 show the composite of the relative vorticity anomalies for $\mathrm{Case}^{+}$(6 RWB cases) and Case- (8 RWB cases) every 2 days from day -4 to day +4 , respectively. In $\mathrm{Case}+$, the upper-level quasi-stationary SWP is clearly seen along the Asian jet, particularly over a region from the Tibetan Plateau to the seas east of Japan, during a period from day -4 to day 0 (Figs. $8 \mathrm{a}, \mathrm{c}, \mathrm{e})$, indicating the influence of the more enhanced SWP along the Asian jet on the stronger RWB. The anomalous anticyclonic circulation seen over the Tibetan Plateau corresponds to the amplified Tibetan High over its eastern part compared to the climatology (Fig. 2a), showing one of the SWP wave sources. In the lower troposphere, the PJ pattern is clearly seen from day 0 to day +2 (Figs. $8 \mathrm{f}$, h), showing the influence of the stronger RWB on the more enhanced PJ pattern. In Case-, in contrast, the upper-level wave propagation along the Asian jet and the consequent RWB is quite weak (Figs. 9a, c, e) compared to the composite for the 44 RWB cases (Figs. 3d, g). The subsequent formation of the PJ pattern following the weaker RWB is also suppressed (Figs. 9f, h) compared to the composite for the 44 RWB cases (Figs. 3i, 1). The case classification by RWB strength shows that the more enhanced SWP along the Asian jet can more efficiently excite the PJ pattern through the stronger RWB east of Japan, and vice versa.

\section{Dynamically induced ascent resulting from the RWB}

To examine the detailed influence of the RWB east of Japan on the enhanced convection east of the Philippines, $\boldsymbol{Q}$-vector diagnosis and associated vorticity budget analysis are conducted for the composite circulation. First, we examine the relationship between the RWB strength and upper-level high PV intrusion toward the subtropical WNP. Figure 10 shows a scatter diagram of the 5-day averaged WB index and 200-hPa anomalous absolute vorticity advection by horizontal wind (RHS in Eq. 5) averaged over $\left[15-25^{\circ} \mathrm{N}, 130-\right.$ $\left.170^{\circ} \mathrm{E}\right]$ (dashed green rectangle labeled " $\mathrm{A}$ " in Fig. $7 \mathrm{~d}$, hereafter referred to as "region A") on day 0 . It shows the relationship between the RWB strength and the consequent enhanced intrusion of the high PV to its south with a significant correlation coefficient $(+0.37)$ at a confidence level of $90 \%$, corresponding to the result of the composite analysis for the cases classified by the WB index (Figs. 8, 9). A higher correlation coefficient $(+0.44)$ at a confidence level of $99 \%$ is obtained when the WB index on day -1 is applied (not shown). The time-lagged relationship shows that the 
(a) $200 \mathrm{hPa}(\mathrm{day}-4)$

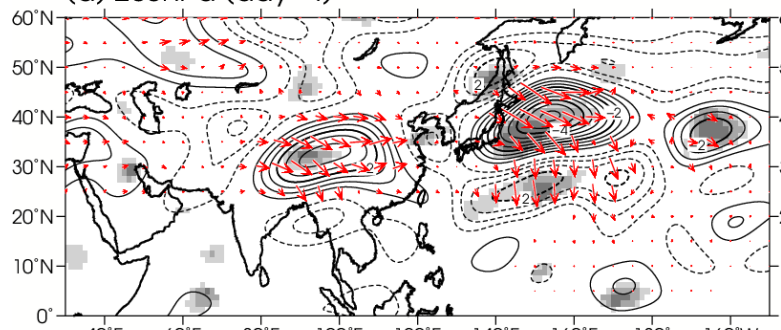

(c) $\left.200 \mathrm{hPa}(\mathrm{day}-2)^{\circ}\right)^{\circ}$ (b) $850 \mathrm{hPa}$ (day-4)

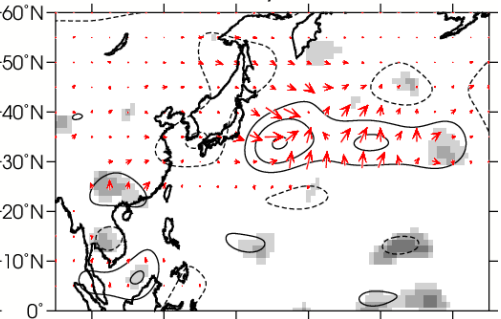

(d) $8500^{120^{\circ} \mathrm{EPa}} \quad{ }^{140^{\circ} \mathrm{E}} \quad 160^{\circ} \mathrm{E}$

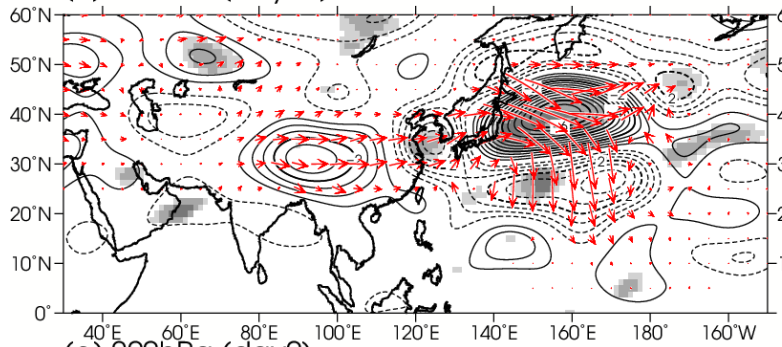

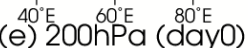
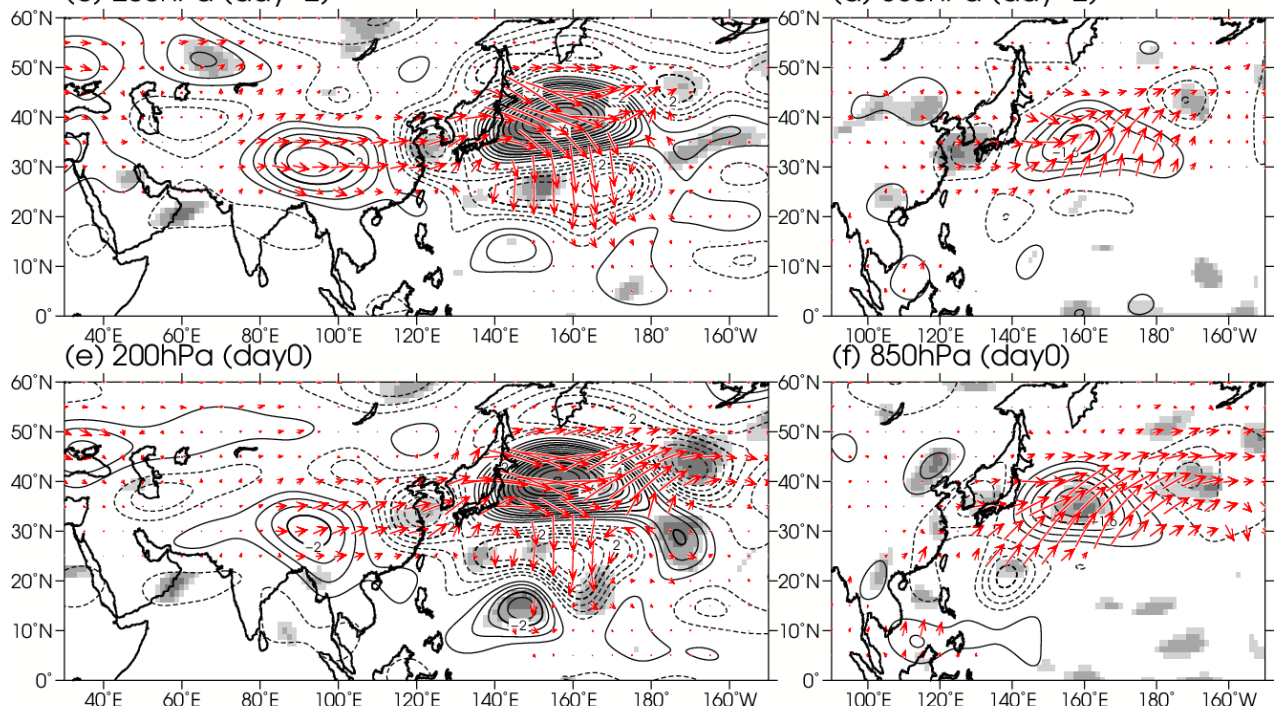

(g) $200 \mathrm{hPa}\left(0^{\circ} \mathrm{Eay}+20^{\circ} \mathrm{E}\right.$
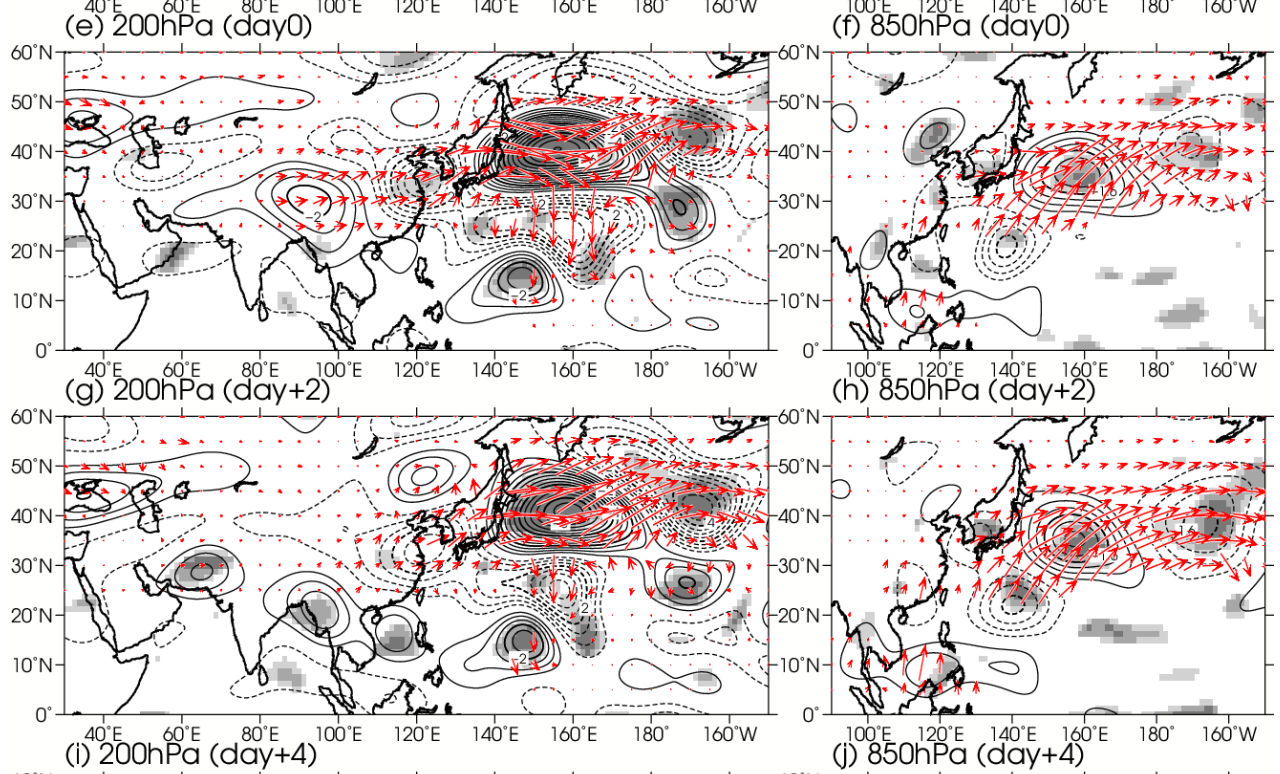

$100^{\circ} \mathrm{E} 120^{\circ} \mathrm{E} \quad 140^{\circ} \mathrm{E} \quad 160^{\circ} \mathrm{E}$
(h) $850 \mathrm{hPa}(\mathrm{day}+2)$

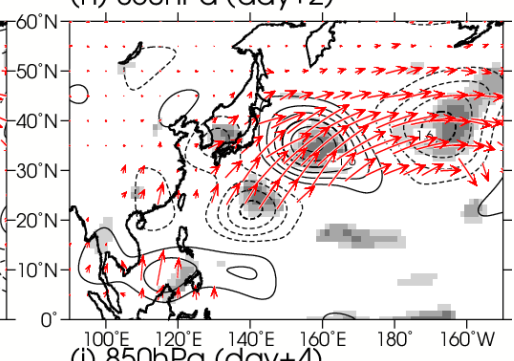

(j) $8500^{\circ} \mathrm{hPa}(\mathrm{day}+4)$
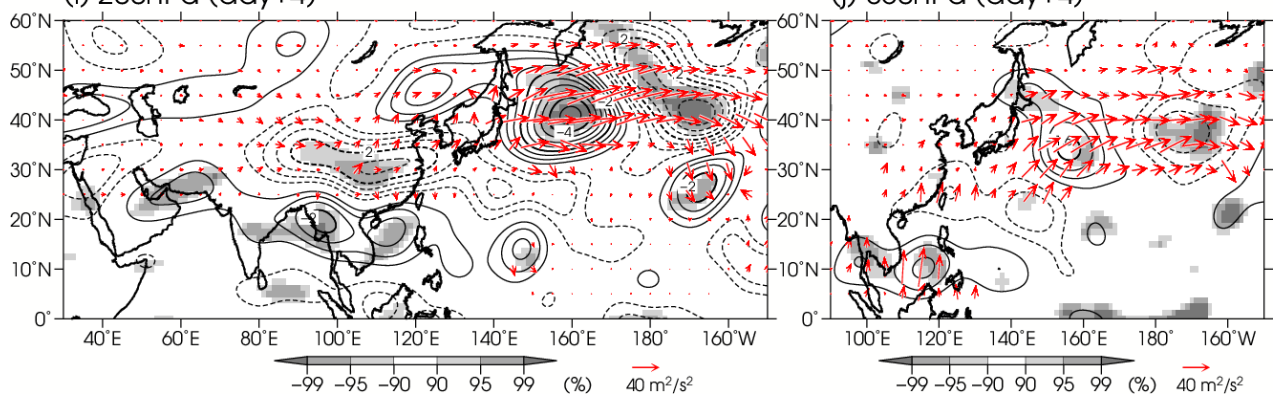

Fig. 8. Composite of (left) 200-hPa and (right) 850-hPa anomalous relative vorticity (contour; unit: $10^{-5} \mathrm{~s}^{-1}$ ) for the six RWB cases $(\mathrm{Case}+)$ with an WB index on day 0 that exceeded +1 standard deviations of the composite. Solid and dashed contours denote negative and positive vorticity anomalies, respectively. Counter intervals are (left) $0.5 \times 10^{-5} \mathrm{~s}^{-1}$ and (right) $0.4 \times 10^{-5} \mathrm{~s}^{-1}$. Red vectors indicate the WAF (unit: $\mathrm{m}^{2} \mathrm{~s}^{-2}$ ). Gray shading indicates the significance level of the difference in the anomalous relative vorticity compared to the composite of the 44 RWB cases. $(\mathrm{a}, \mathrm{b})$ day $-4,(\mathrm{c}, \mathrm{d})$ day $-2,(\mathrm{e}, \mathrm{f})$ day $0,(\mathrm{~g}, \mathrm{~h})$ day +2 , and $(\mathrm{i}, \mathrm{j})$ day +4 . 
(a) 200hPa (day-4)

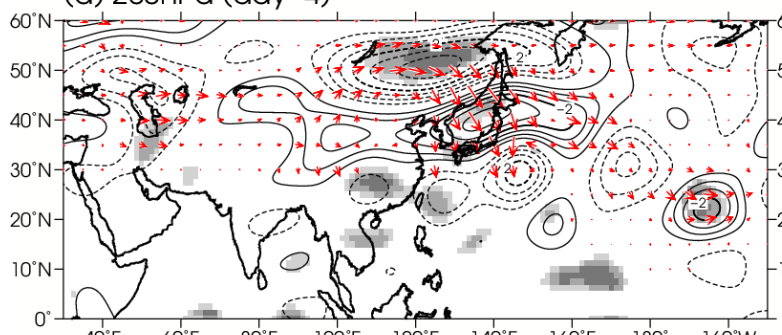

(c) $200 \mathrm{hPa}(\mathrm{day}-2)^{\circ 0^{\circ} \mathrm{E}}$

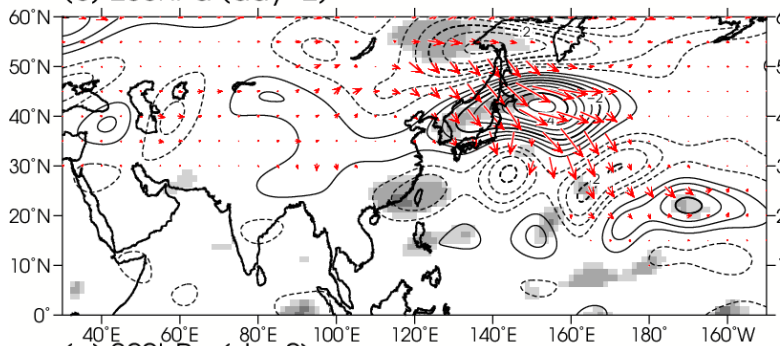

(e) $200 \mathrm{hPa}$ (dayo) (b) $850 \mathrm{hPa}$ (day-4)

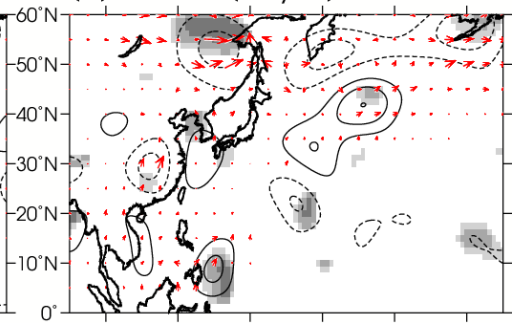

(d) $8500^{120^{\circ} \mathrm{EPa}} \quad{ }^{140^{\circ} \mathrm{E}} \quad 160^{\circ} \mathrm{E}$
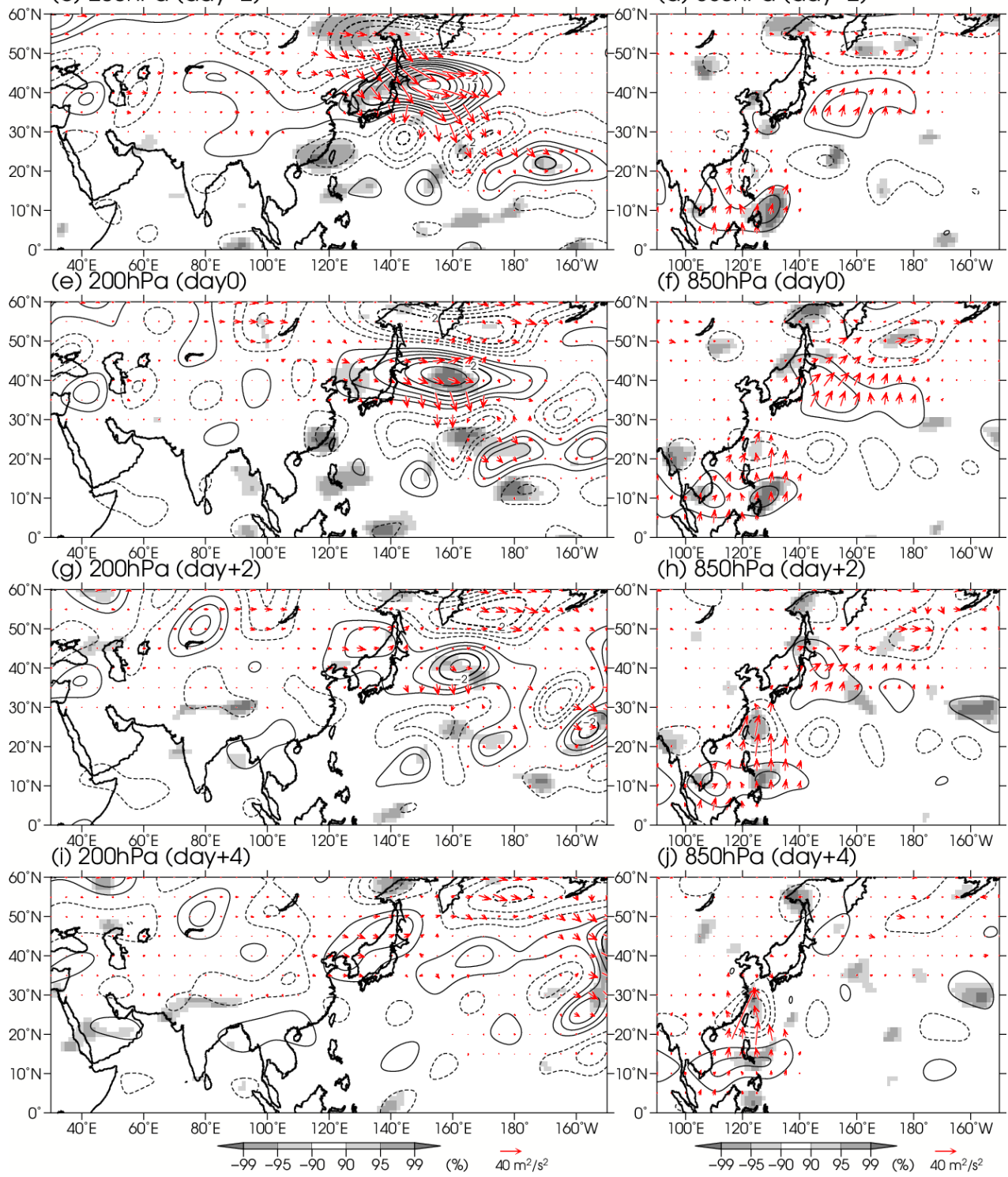

Fig. 9. Same as Fig. 8, but for the eight RWB cases (Cases-) in which the WB index on day 0 was less than -1 standard deviations of the composite. 


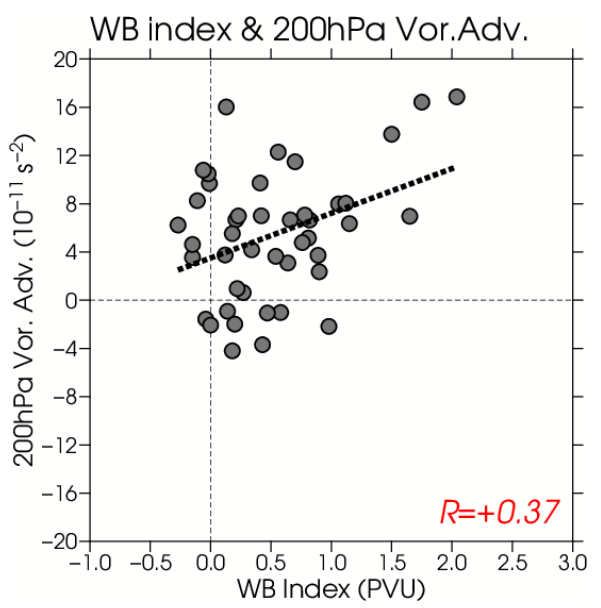

Fig. 10. Scatter diagram of 5-day averaged WB index (X-axis; unit: PVU) and 200-hPa absolute vorticity advection (Y-axis; RHS in Eq. 5; unit: $10^{-11} \mathrm{~s}^{-2}$ ) averaged over region A (Fig. 7) on day 0 for the 44 RWB cases. Dashed line denotes a regression line with a confidence level greater than $90 \%$. The corresponding correlation coefficient $(R)$ is shown at the lower right of the panel.

RWB is followed by the high PV intrusion.

Vertically integrated (from 850 to $200 \mathrm{hPa}$ ) anomalous $\boldsymbol{Q}$-vectors and their divergence calculated from 5-day averages on day 0 are shown in Fig. 11; the dynamical influence of the high PV intrusion associated with the RWB on the vertical motion over the subtropical WNP is evident. The convergence of the $\boldsymbol{Q}$-vector is seen immediately south of the southwestward-intruding high PV over the latitudinal band of $20^{\circ} \mathrm{N}$ over the subtropical WNP, suggesting a greater contribution of the vertical difference in vorticity advection associated with the strong positive vorticity advection in the upper troposphere than that of the mid-tropospheric thermal advection. Figure 12 shows 5-day averaged absolute vorticity advection at 200and $850-\mathrm{hPa}$ and their vertical difference on day 0 . In the upper troposphere, positive vorticity advection is clearly seen over the latitudinal band of $20^{\circ} \mathrm{N}$ east of the Philippines (Fig. 12a), corresponding to the region where the convergence of $\boldsymbol{Q}$-vector is seen (Fig. $11)$. Moreover, positive vorticity advection is seen immediately south of the anomalous positive vorticity because of the RWB (contour in Fig. 12a) and downstream of the trough along the climatological southward flow along the eastern fringe of the Tibetan High (vectors in Fig. 12a). This result indicates the essential role of the anomalous vorticity advected by the clima-

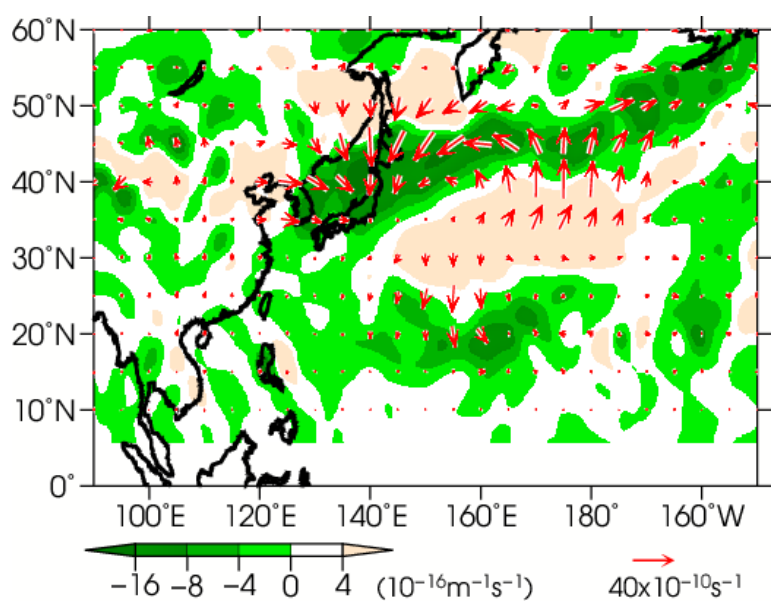

Fig. 11. Composite of vertically integrated anomalous $\boldsymbol{Q}$-vectors (vectors; unit: $\mathrm{s}^{-1}$ ) and their divergence (shading; unit: $\mathrm{m}^{-1} \mathrm{~s}^{-1}$ ) over a region north of $5^{\circ} \mathrm{N}$ derived from 5 -day averages on day 0 . Green shading indicates the convergence of the $\boldsymbol{Q}$-vector. The vertical integration is taken from the $850-\mathrm{hPa}$ to $200-\mathrm{hPa}$ level.

tological wind (i.e., the second term of RHS in Eq. 5). Although vorticity advection is also seen in the lower troposphere primarily because of the climatological absolute vorticity advected by the anomalous wind (i.e., the first term of RHS in Eq. 5) associated with the PJ pattern (Fig. 12b), its amplitude is smaller than that in the upper troposphere (Fig. 12a). The vertical difference in the vorticity advection between the upper and lower troposphere is positive over the latitudinal band of $20^{\circ} \mathrm{N}$ east of the Philippines (Fig. 12c) because of the stronger positive upper-level vorticity advection. These results are consistent with those of Takemura et al. (2017), who indicated the primary importance of the southward positive vorticity advection in the upper troposphere to the enhanced convection in the subtropical WNP in their case study.

The $\boldsymbol{Q}$-vector diagnosis and vorticity budget analysis show that the southwestward intrusion of the upperlevel high PV associated with the RWB acts to dynamically induce ascent to its south, thereby contributing to the enhanced convection east of the Philippines and subsequent formation of the PJ pattern.

\section{Partial correlation analysis of the RWB cases}

To quantitatively show the relative importance of the possible factors in the enhanced convection east of the Philippines and formation of the PJ pattern com- 
pared to the anomalous SST, we performed a partial correlation analysis of the 44 RWB cases. Here, the contribution rate of each explanatory variable was estimated from the magnitude of the standardized partial regression coefficient. Unless otherwise noted, the variables to calculate the correlation are defined as 5-day mean areal averages over region A on day 0 except for SST, which is averaged from day -15 to day -6 .

\subsection{Relative importance of enhanced convection and SST to formation of the PJ pattern}

Figure 13 shows the relationship of 5-day averaged $500-\mathrm{hPa}$ anomalous vertical $p$-velocity and anomalous SST to the PJ index. Figure 13a shows a strong relationship between the enhanced convection east of the Philippines and formation of the PJ pattern with a high correlation coefficient $(-0.70)$ at a confidence level of $99 \%$, consistent with the result of Nitta (1987). It is also evident that a warmer SST condition contributes to enhancement of the PJ pattern (color in Fig. 13a). Although a positive correlation between the anomalous SST and PJ index is seen, its magnitude is much smaller than the correlation between the 500$\mathrm{hPa}$ anomalous vertical velocity and $\mathrm{PJ}$ index and is not significant (Fig. 13c). The relationship between the enhanced convection and PJ index remains strong even without the variability associated with the anomalous SST, with a high partial correlation coefficient of -0.68 (Fig. 13b). In contrast, the relationship between the anomalous SST and PJ index clearly decreases without the variability associated with the enhanced convection, with a nearly zero partial correlation (Fig. 13d). The contribution rates of the enhanced convection and anomalous SST to the PJ index are estimated as $72 \%$ and $5 \%$, respectively. The partial correlation analysis shows that the enhanced convection east of the Philippines is primarily important to the formation of the PJ pattern.

\subsection{Relative importance of the positive vorticity advection and SST to enhanced convection}

To emphasize the primary importance of the RWB to the enhanced convection, the relationship of 5-day averaged $200-\mathrm{hPa}$ anomalous absolute vorticity advection by a horizontal wind (RHS in Eq. 5) and an anomalous SST to the $500-\mathrm{hPa}$ anomalous vertical $p$-velocity is shown in Fig. 14. Figure 14a shows the strong relationship between the upper-level positive vorticity advection associated with the RWB and enhanced convection east of the Philippines, with a high correlation coefficient $(-0.53)$ at a confidence level of

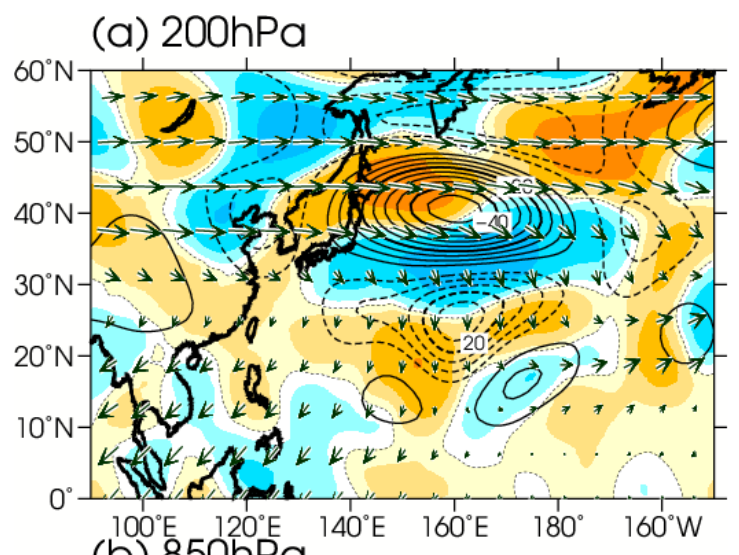

(b) $850 \mathrm{hPa}$
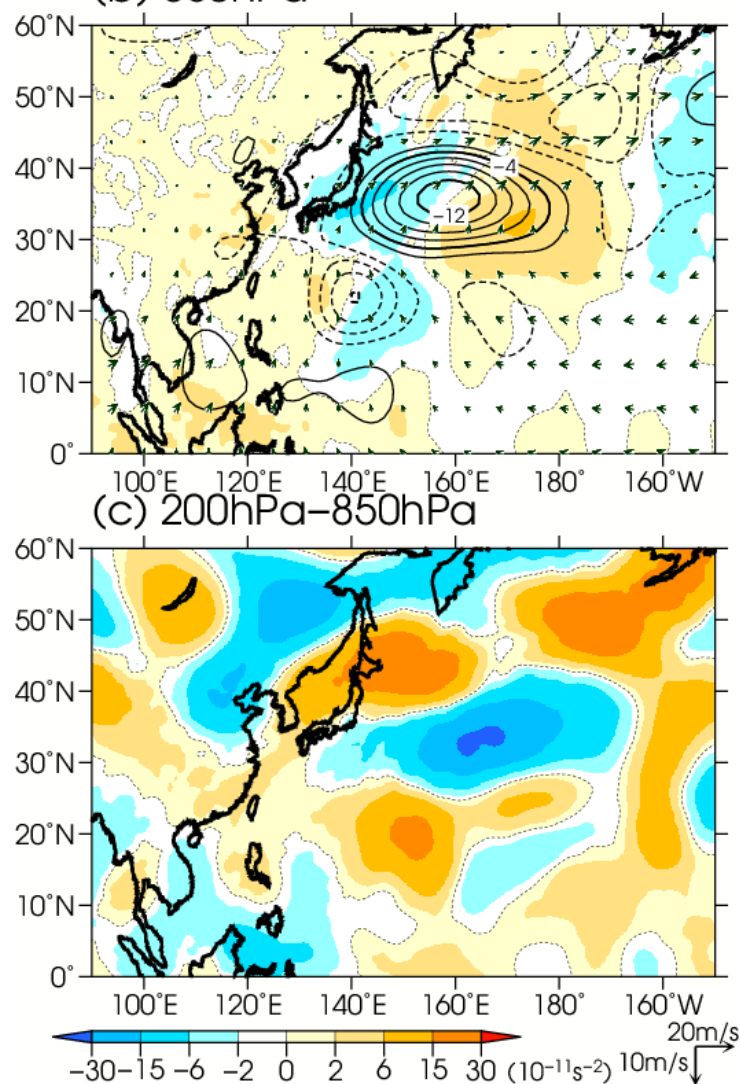

Fig. 12. Composite for 5-day averaged (a) 200$\mathrm{hPa}$, (b) $850-\mathrm{hPa}$, and (c) vertical differences (200-hPa minus $850-\mathrm{hPa}$ ) in anomalous absolute vorticity advection (shading; unit: $10^{-11} \mathrm{~s}^{-2}$; RHS of Eq. 5) by the horizontal wind on day 0. Contours and vectors in $(\mathrm{a}, \mathrm{b})$ show the anomalous relative vorticity (unit: $10^{-6} \mathrm{~s}^{-1}$ ) and climatological horizontal wind, respectively. Solid and dashed contours in (a) and (b) denote negative and positive vorticity anomalies, respectively. The contour intervals are (a) $5 \times 10^{-6} \mathrm{~s}^{-1}$ and (b) $2 \times 10^{-6} \mathrm{~s}^{-1}$. 
(a) 500hPa P-vel anom. \& PJ index

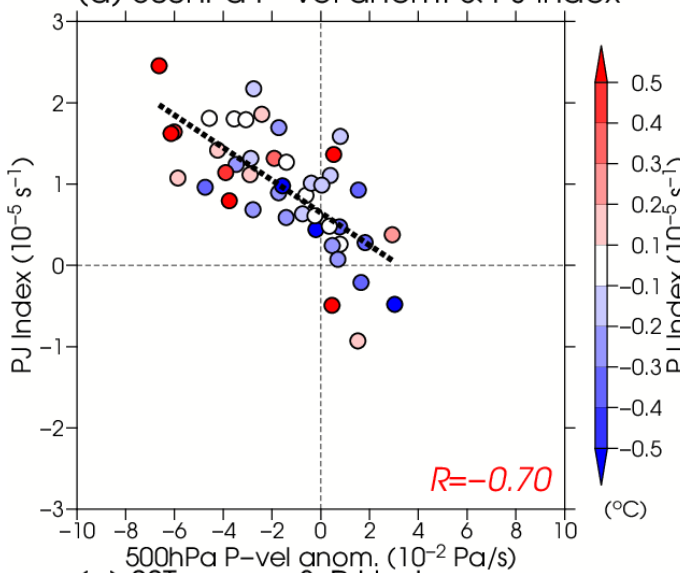

(c) SST anom. \& PJ index

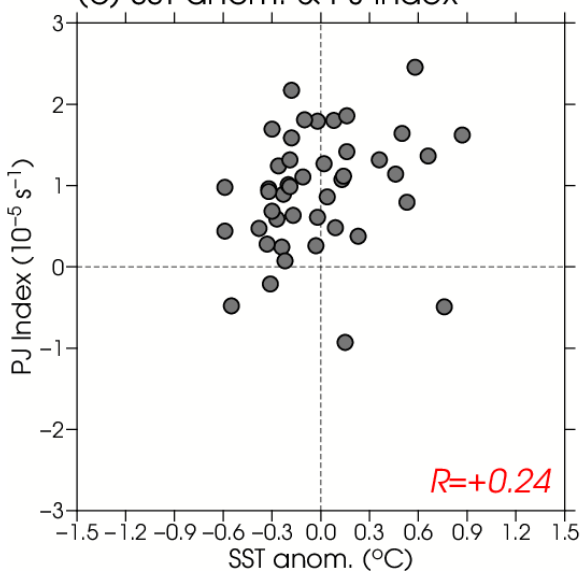

(b) 500hPa P-vel anom. \& PJ index

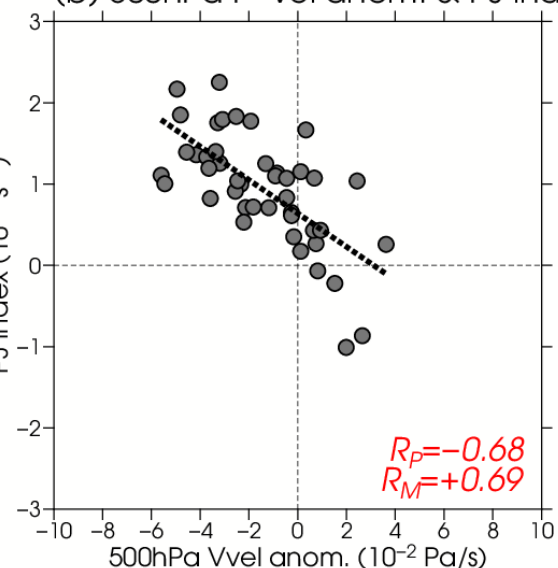

(d) SST anom. \& PJ index

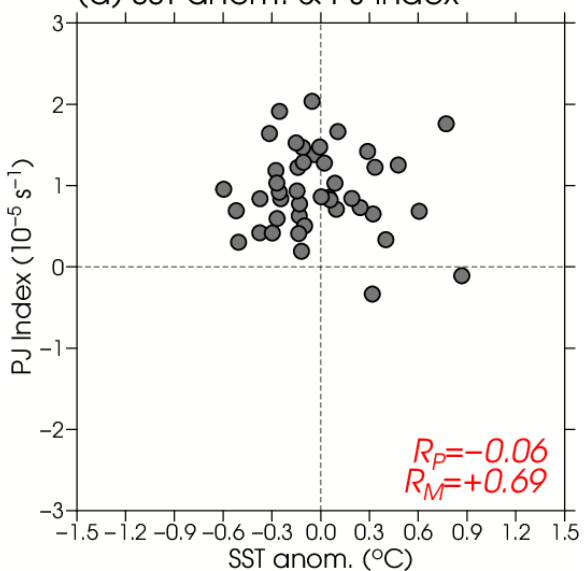

Fig. 13. Same as Fig. 10, but for (a, b) 500-hPa anomalous vertical $p$-velocity (X-axis; unit: $10^{-2} \mathrm{~Pa} \mathrm{~s}^{-1}$ ) and PJ index (Y-axis; unit: $10^{-5} \mathrm{~s}^{-1}$ ), and (c, d) anomalous SST (X-axis; unit: ${ }^{\circ} \mathrm{C}$ ) and PJ index (Y-axis). Anomalous 500$\mathrm{hPa}$ vertical $p$-velocity and SST is averaged over region A. Anomalous SST in each case is represented by color in (a). In (b) and (d), the variability explained by the anomalous SST and 500-hPa vertical $p$-velocity is removed using the partial regression, respectively. The corresponding partial correlation coefficient $\left(R_{P}\right)$ and multiple correlation coefficient $\left(R_{M}\right)$ are shown at the lower right of the panel in (b) and (d), respectively.

$99 \%$. The color shown in Fig. 14a and scatter in Fig. $14 \mathrm{c}$ show that a warmer SST condition also is related to the enhanced convection, with a correlation coefficient of -0.40 , although its magnitude is smaller than that of the correlation between the upper-level vorticity advection and convection. The relationship between the upper-level vorticity advection and enhanced convection remains strong even without the variability associated with the anomalous SST, with a partial correlation coefficient of -0.48 (Fig. 14b). The relationship between the anomalous SST and the enhanced convection weakens without the variability associated with the upper-level vorticity advection, with a partial correlation coefficient of -0.32 (Fig. 14d). The contri- bution rates of the upper-level vorticity advection and anomalous SST to the enhanced convection are estimated as $46 \%$ and $28 \%$, respectively, indicating that the upper-level positive vorticity advection associated with the RWB is primarily important for the enhanced convection east of the Philippines.

\subsection{Relative importance of the positive vorticity advection and SST to formation of the PJ pattern}

Furthermore, the primary importance of the RWB to formation of the PJ pattern should also be described. Figure 15 shows the relationship of 5-day averaged 200-hPa anomalous absolute vorticity advection by horizontal wind and anomalous SST to the PJ index. 
(a) 200hPa Vor.Adv. \& 500hPa P-vel

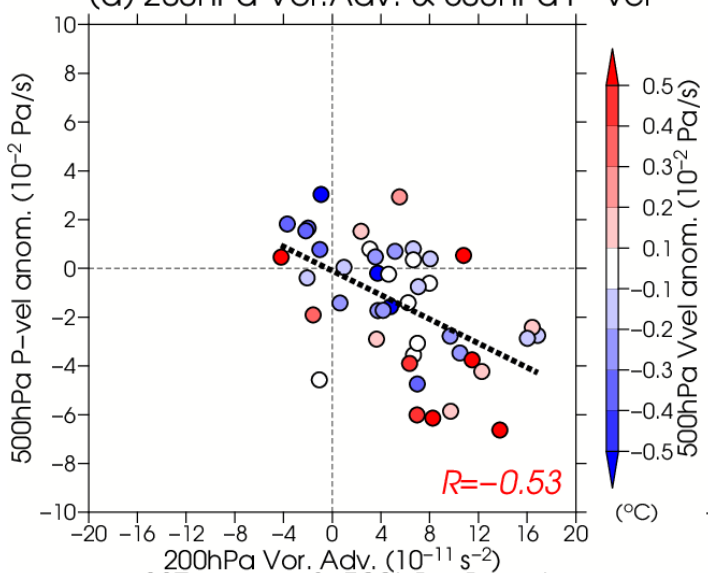

(c) SST anom. \& 500hPa P-vel anom.

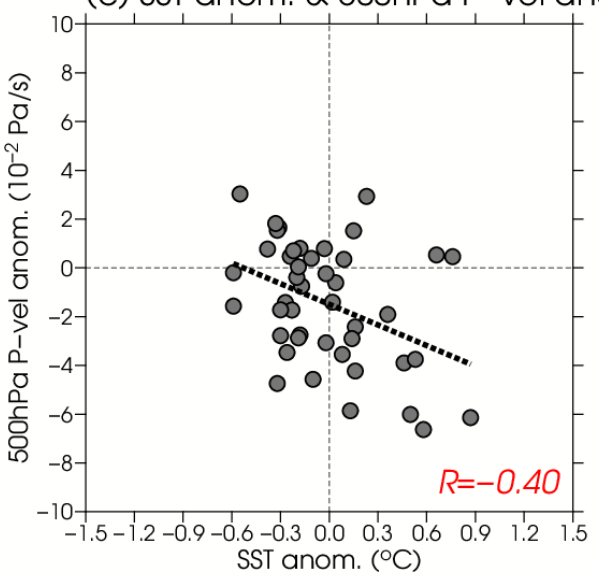

(b) $200 \mathrm{hPa}$ Vor.Adv. \& 500hPa P-vel

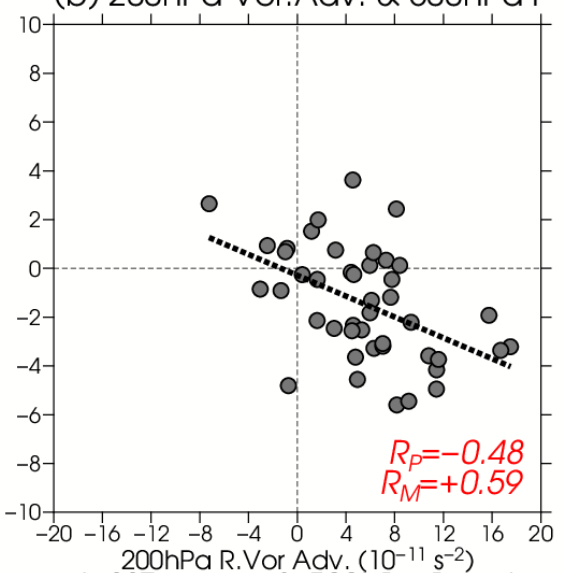

(d) SST anom. \& 500hPa P-vel anom.

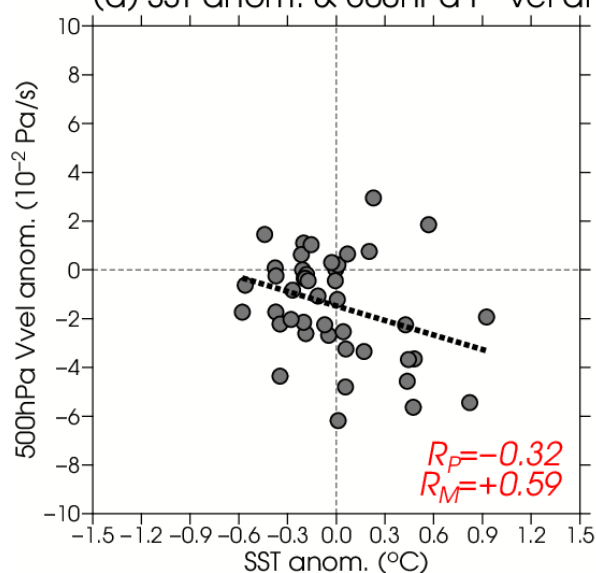

Fig. 14. Same as Fig. 13, but for (a, b) 200-hPa anomalous absolute vorticity advection by the horizontal wind (X-axis; unit: $10^{-11} \mathrm{~s}^{-2}$ ) and 500-hPa anomalous vertical $p$-velocity (Y-axis; unit: $10^{-2} \mathrm{~Pa} \mathrm{~s}^{-1}$ ), and (c, d) anomalous SST (X-axis; unit: ${ }^{\circ} \mathrm{C}$ ) and 500-hPa anomalous vertical $p$-velocity (Y-axis). In (b) and (d), the variability explained by the anomalous SST and $200-\mathrm{hPa}$ absolute vorticity advection is removed, respectively.

Figure 15a shows a strong relationship between the upper-level positive vorticity advection associated with the RWB and the enhanced PJ pattern, with a high correlation coefficient $(+0.57)$ at a confidence level of $99 \%$. There are a few RWB cases of negative PJ indices (Fig. 15a) and they show a negative or weak positive vorticity advection in the upper troposphere, indicating that cases which exhibit insufficient enhancement of the PJ pattern are associated with a weak RWB. A contribution of a warmer SST condition to the enhancement of the PJ pattern is also evident (color in Fig. 15a). Although a positive correlation coefficient between the anomalous SST and PJ index $(+0.24)$ is seen, its magnitude is much smaller than that of the correlation between the upper-level vorticity advection and PJ index and is not significant
(Fig. 15c). The relationship between the upper-level vorticity advection and the enhanced PJ pattern remains strong without the variability associated with the anomalous SST, with a partial correlation coefficient of +0.54 (Fig. 15b). In contrast, the relationship between the anomalous SST and the PJ index significantly weakens without the variability associated with the upper-level vorticity advection, with a low partial correlation coefficient of +0.11 (Fig. 15d). The contribution rates of the upper-level vorticity advection and anomalous SST to the enhanced PJ pattern are estimated as $54 \%$ and $10 \%$, respectively, indicating that the upper-level positive vorticity advection associated with the RWB is primarily important to enhancement of the PJ pattern.

These partial correlation analysis results indicate 
(a) 200hPa Vor.Adv. \& PJ index

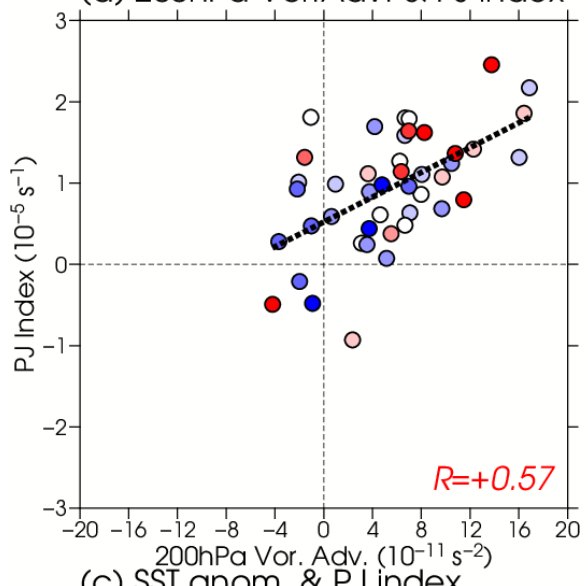

(c) SST anom. \& PJ index

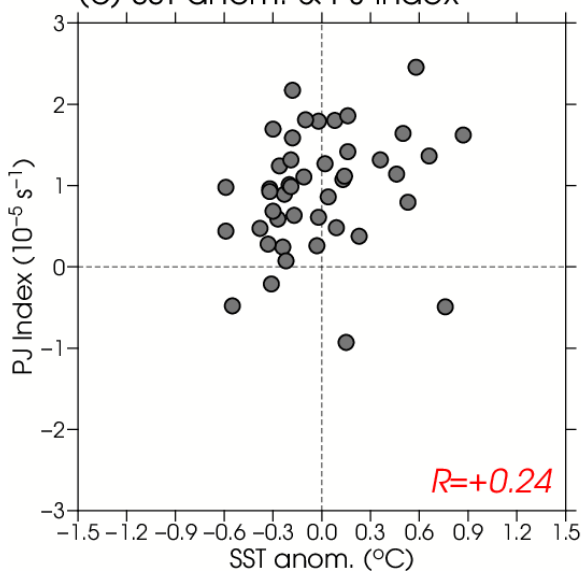

(b) 200hPa Vor.Adv. \& PJ index

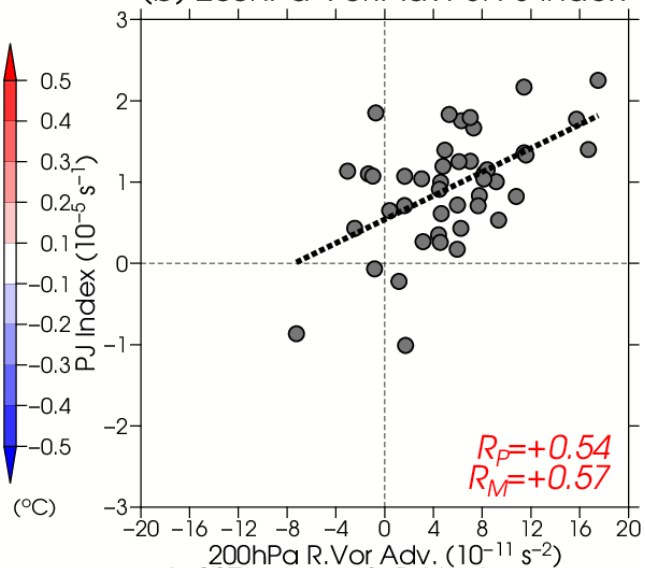

(d) SST anom. \& PJ index

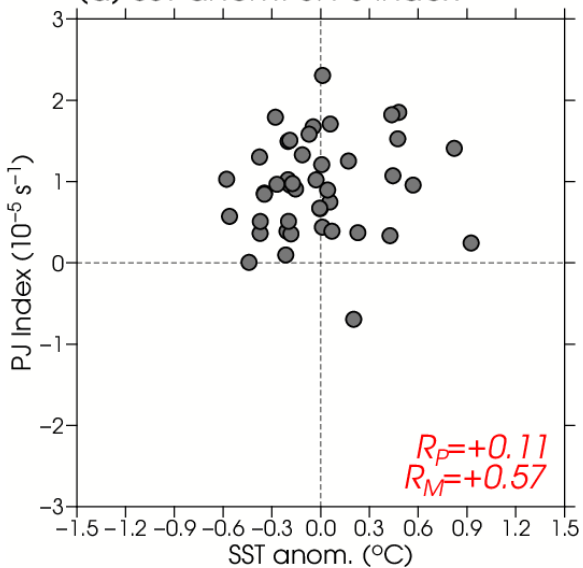

Fig. 15. Same as Fig. 13, but for (a, b) 200-hPa anomalous absolute vorticity advection by the horizontal wind (X-axis; unit: $10^{-11} \mathrm{~s}^{-2}$ ) and PJ index (Y-axis; unit: $\left.10^{-5} \mathrm{~s}^{-1}\right)$, and (c, d) anomalous SST (X-axis; unit: $\left.{ }^{\circ} \mathrm{C}\right)$ and PJ index (Y-axis).

the primary importance of the upper-level high PV intrusion associated with the RWB to formation of the PJ pattern through enhanced convection east of the Philippines, compared to that of the anomalous SST conditions.

\section{Conclusion and discussion}

To show a possible process linking the quasistationary SWP along the Asian jet and the PJ pattern through the RWB during boreal summer and its statistical significance, we conducted a lag composite analysis for the past 44 RWB events east of Japan, using the JRA-55 reanalysis dataset. The lag composite anomalies show that the SWP along the Asian jet induces the RWB east of Japan with an "inverse-S" shaped meridional overturning of the upper-level PV distribution. An anticyclonic RWB is accompanied by a southwestward intrusion of the high PV toward the subtropical WNP in the upper troposphere. The $\boldsymbol{Q}$-vector diagnosis and vorticity budget analysis indicate that the equatorward positive vorticity advection in the upper troposphere is important to the dynamically induced ascent and enhanced convection east of the Philippines. The enhanced convection in this area is accompanied by formation of the PJ pattern. Case classification by RWB strength indicates that the stronger RWB is significantly related to the more enhanced preceding SWP and subsequent enhanced PJ pattern, and vice versa. A partial correlation analysis of the 44 RWB cases was performed to quantitatively assess the relative importance of the upper-level positive vorticity advection and warm SST over the subtropical WNP to the enhanced convection in this area and formation of the PJ pattern. It was found that 
the upper-level positive vorticity advection is a more crucial factor reinforcing the active convection and PJ pattern than the warm SST conditions. These results indicate the existence of a relationship in which the more enhanced SWP along the Asian jet can more efficiently excite the PJ pattern through the stronger RWB east of Japan.

All 44 RWB cases extracted in this study were categorized as an anticyclonic type associated with the anticyclonically sheared basic state south of the jet core. An anticyclonic RWB is expected to be favorable to the southwestward intrusion of high PV toward the subtropical WNP, and hence formation of the PJ pattern, compared to a cyclonic RWB. This perspective motivates us to further analyze more RWB cases including a few that are cyclonic in terms of the influence of the morphology of the RWB on formation of the PJ pattern.

It is well known that the active convection over the subtropical WNP and enhanced PJ pattern is closely related to the active phase of the Madden Julian Oscillation (MJO) propagating near the Maritime Continent (Molinari and Vollaro 2012, 2017), as well as the extratropical variability shown in this study. Figure 16a shows a longitude-time cross section of $200-\mathrm{hPa}$ anomalous velocity potential near the equator from day -15 to day +15 . There is no significant eastward propagation of the MJO phase before day -5 , and suppressed convection associated with an inactive $\mathrm{MJO}$ phase is clearly seen around $120^{\circ} \mathrm{E}$ near the Maritime Continent from day -4 to day +4 . It is also well known that the boreal summer intra-seasonal oscillation (BSISO; Kikuchi et al. 2012; Lee et al. 2013) is activated during boreal summer, and is characterized as the northward propagation of active and inactive phases of convective activities over the Asian monsoon region. To assess the influence of the BSISO, a time-latitude cross section for a composite of anomalous 200-hPa velocity potential and 500$\mathrm{hPa}$ vertical $p$-velocity over the longitudinal band of the Asian monsoon region is shown in Fig. 16b. There is no signal of the northward propagation of the anomalous ascent and the upper-level divergence anomalies during the period of the RWB cases. Although a stationary anomalous descent is seen along the latitudinal band of $5-15^{\circ} \mathrm{N}$, its amplitude is quite small. The characteristics of the composite anomalies suggest that the contribution of the active phase of the intra-seasonal oscillation to the enhanced convection east of the Philippines and formation of the PJ pattern is small during the period of the RWB cases compared to that of the extratropical variability. However, nota- (a) Chi200 anom.

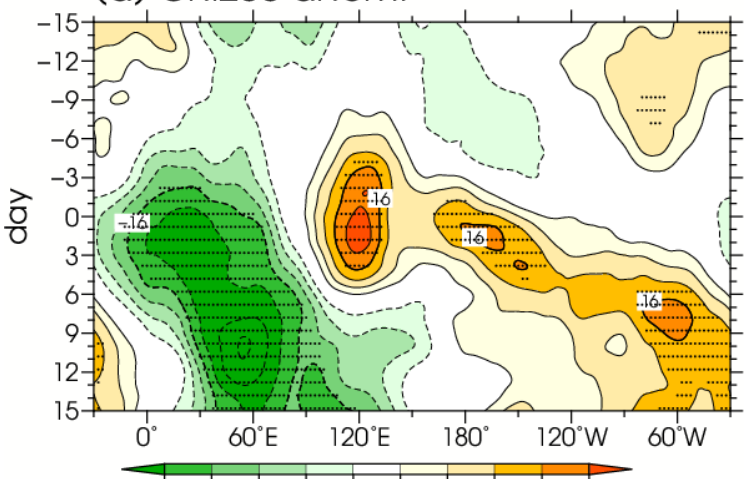

$-20-16-12 \quad-8 \quad-4 \quad 4 \quad 8 \quad 12 \quad 16 \quad 20\left(10^{6} m^{2} s^{-1}\right)$

(b) $\mathrm{Chi}^{-20}-10^{-8}$ \& Ömg500 anom.

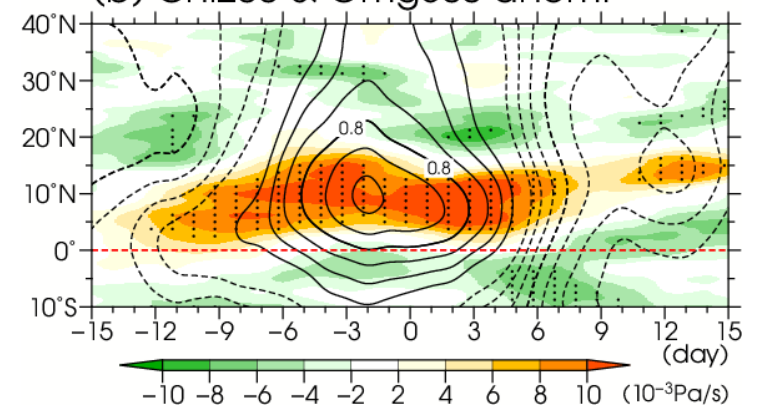

Fig. 16. (a) Hovmöller diagram of composited 5-day mean $200-\mathrm{hPa}$ anomalous velocity potential (unit: $10^{6} \mathrm{~m}^{2} \mathrm{~s}^{-1}$ ) averaged between $5^{\circ} \mathrm{S}$ and $5^{\circ} \mathrm{N}$ from day -15 to day +15 , and (b) timelatitude cross section of composited 5-day mean $200-\mathrm{hPa}$ anomalous velocity potential (contour) and 500-hPa anomalous vertical $p$-velocity (shading; unit: $10^{-3} \mathrm{~Pa} \mathrm{~s}^{-1}$ ) averaged between $60^{\circ} \mathrm{E}$ and $150^{\circ} \mathrm{E}$. Solid (dashed) contours denote the upper-level large-scale convergence (divergence) anomalies associated with inactive (active) phase of the tropical convection. Black dots indicate statistical significance at a $95 \%$ level of the (a) anomalous velocity potential and (b) anomalous vertical $p$-velocity.

bly, the extracted 44 RWB cases include a few cases affected by intra-seasonal oscillation such as the case shown by JMA (2013). Also notable is that an active phase of tropical convection is clearly seen over the longitudinal bands between $0^{\circ}$ and $60^{\circ} \mathrm{E}$ from day -2 , and it propagates eastward toward the Indian Ocean (Fig. 16). Although the tropical convective activity including the active MJO phase can excite the SWP along the Asian jet (e.g., Rodwell and Hoskins 1996) preceding the RWB, this process is outside the scope of the present paper. Further investigation is needed to 
assess the detailed influence of the tropical atmospheric variability on the process linking the SWP along the Asian jet and formation of the PJ pattern.

\section{Acknowledgments}

The authors are very grateful to Dr. Takeshi Horinouchi and two anonymous reviewers for their constructive and helpful comments. The Generic Mapping Tools (GMT) were used to create the graphics. This study was partly supported by the JSPS KAKENHI Grant (18H01280, 18K03734).

\section{References}

Abatzoglou, J. T., and G. Magnusdottir, 2006: Planetary wave breaking and nonlinear reflection: Seasonal cycle and interannual variability. J. Climate, 19, 6139-6152.

Bowley, K. A., J. R. Gyakum, and E. H. Atallah, 2019: A new perspective toward cataloging Northern Hemisphere Rossby wave breaking on the dynamical tropopause. Mon. Wea. Rev., 147, 409-431.

Duchon, C. E, 1979: Lanczos filtering in one and two dimensions. J. Appl. Meteor., 18, 1016-1022.

Enomoto, T., 2004: Interannual variability of the Bonin high associated with the propagation of Rossby waves along the Asian jet. J. Meteor. Soc. Japan, 82, 10191034.

Enomoto, T., B. J. Hoskins, and Y. Matsuda, 2003: The formation mechanism of the Bonin high in August. Quart. J. Roy. Meteor. Soc., 129, 157-178.

Funatsu, B. M., and D. W. Waugh, 2008: Connections between potential vorticity intrusions and convection in the eastern tropical Pacific. J. Atmos. Sci., 65, 9871002 .

Hitchman, M. H., and A. S. Huesmann, 2007: A seasonal climatology of Rossby wave breaking in the 3202000-K layer. J. Atmos. Sci., 64, 1922-1940.

Holton, J. R., 1992: An Introduction to Dynamic Meteorology. 3rd Edition. Academic Press, 507 pp.

Homeyer, C. R., and K. P. Bowman, 2013: Rossby wave breaking and transport between the tropics and extratropics above the subtropical jet. J. Atmos. Sci., 70, 607-626.

Horinouchi, T., 2014: Influence of upper tropospheric disturbances on the synoptic variability of precipitation and moisture transport over summertime East Asia and the northwestern Pacific. J. Meteor. Soc. Japan, 92, 519541.

Hoskins, B. J., and T. Ambrizzi, 1993: Rossby wave propagation on a realistic longitudinally varying flow. $J$. Atmos. Sci., 50, 1661-1671.

Hoskins, B. J., I. Draghici, and H. C. Davies, 1978: A new look at the $\omega$-equation. Quart. J. Roy. Meteor. Soc., 104, 31-38.

Imada, Y., M. Watanabe, H. Kawase, H. Shiogama, and M. Arai, 2019: The July 2018 high temperature event in Japan could not have happened without humaninduced global warming. SOLA, 15A, 8-12.

Ishii, M., A. Shouji, S. Sugimoto, and T. Matsumoto, 2005: Objective analyses of sea-surface temperature and marine meteorological variables for the 20th century using ICOADS and the Kobe collection. Int. J. Climatol., 25, 865-879.

Japan Meteorological Agency, 2013: Extremely hot latesummer conditions in northern and eastern Japan in 2012. Annual Report on the Climate System 2012. $55-63 \mathrm{pp}$.

Kawamura, R., M. Sugi, T. Kayahara, and N. Sato, 1998: Recent extraordinary cool and hot summers in East Asia simulated by an ensemble climate experiment. $J$. Meteor. Soc. Japan, 76, 597-617.

Kawamura, R., T. Matsuura, and S. Iizuka, 2001: Interannual atmosphere-ocean variations in the tropical western North Pacific relevant to the Asian summer monsoonENSO coupling. J. Meteor. Soc. Japan, 79, 883-898.

Kikuchi, K., B. Wang, and Y. Kajikawa, 2012: Bimodal representation of the tropical intraseasonal oscillation. Climate Dyn., 38, 1989-2000.

Kobayashi, S., Y. Ota, Y. Harada, A. Ebita, M. Moriya, H. Onoda, K. Onogi, H. Kamahori, C. Kobayashi, H. Endo, K. Miyaoka, and K. Takahashi, 2015: The JRA-55 Reanalysis: General specifications and basic characteristics. J. Meteor. Soc. Japan, 93, 5-48.

Kosaka, Y., and H. Nakamura, 2006: Structure and dynamics of the summertime Pacific-Japan teleconnection pattern. Quart. J. Roy. Meteor. Soc., 132, 2009-2030.

Kosaka, Y., and H. Nakamura, 2010: Mechanisms of meridional teleconnection observed between a summer monsoon system and a subtropical anticyclone. Part I: The Pacific-Japan pattern. J. Climate, 23, 5085-5108.

Kosaka, Y., H. Nakamura, M. Watanabe, and M. Kimoto, 2009: Analysis on the dynamics of a wave-like teleconnection pattern along the summertime Asian jet based on a reanalysis dataset and climate model simulations. J. Meteor. Soc. Japan, 87, 561-580.

Lee, J.-Y., B. Wang, M. C. Wheeler, X. Fu, D. E. Waliser, and I.-S. Kang, 2013: Real-time multivariate indices for the boreal summer intraseasonal oscillation over the Asian summer monsoon region. Climate Dyn., 40, 493-509.

Lu, R., and B. W. Dong, 2001: Westward extension of North Pacific subtropical high in summer. J. Meteor. Soc. Japan, 79, 1229-1241.

Lu, R.-Y., J.-H. Oh, and B.-J. Kim, 2002: A teleconnection pattern in upper-level meridional wind over the North African and Eurasian continent in summer. Tellus A, 54, 44-55.

Matthews, A. J., and G. N. Kiladis, 2000: A model of Rossby waves linked to submonthly convection over the eastern tropical Pacific. J. Atmos. Sci., 57, 37853798.

Molinari, J., and D. Vollaro, 2012: A subtropical cyclonic 
gyre associated with interactions of the MJO and the midlatitude jet. Mon. Wea. Rev., 140, 343-357.

Molinari, J., and D. Vollaro, 2017: Monsoon gyres of the northwest Pacific: Influences of ENSO, the MJO, and the Pacific-Japan pattern. J. Climate, 30, 1765-1777.

Nitta, T., 1987: Convective activities in the tropical western Pacific and their impact on the Northern Hemisphere summer circulation. J. Meteor. Soc. Japan, 65, 373390.

Pelly, J. L., and B. J. Hoskins, 2003: A new perspective on blocking. J. Atmos. Sci., 60, 743-755.

Postel, G. A., and M. H. Hitchman, 1999: A climatology of Rossby wave breaking along the subtropical tropopause. J. Atmos. Sci., 56, 359-373.

Postel, G. A., and M. H. Hitchman, 2001: Observational diagnosis of a Rossby wave breaking event along the subtropical tropopause. Mon. Wea. Rev., 129, 25552569.

Rodwell, M. J., and B. J. Hoskins, 1996: Monsoons and the dynamics of deserts. Quart. J. Roy. Meteor. Soc., 122, 1385-1404.

Rodwell, M. J., and B. J. Hoskins, 2001: Subtropical anticyclones and summer monsoons. J. Climate, 14, 3192-3211.

Sato, N., K. Sakamoto, and M. Takahashi, 2005: An air mass with high potential vorticity preceding the formation of the Marcus Convergence Zone. Geophys. Res. Lett., 32, L17801, doi:10.1029/2005GL023572.

Sekizawa, S., T. Miyasaka, H. Nakamura, A. Shimpo, K. Takemura, and S. Maeda, 2019: Anomalous moisture transport and oceanic evaporation during a torrential rainfall event over western Japan in early July 2018. SOLA, 15A, 25-30.
Shimpo, A., K. Takemura, S. Wakamatsu, H. Togawa, Y. Mochizuki, M. Takekawa, S. Tanaka, K. Yamashita, S. Maeda, R. Kurora, H. Murai, N. Kitabatake, H. Tsuguti, H. Mukougawa, T. Iwasaki, R. Kawamura, M. Kimoto, I. Takayabu, Y. N. Takayabu, Y. Tanimoto, T. Hirooka, Y. Masumoto, M. Watanabe, K. Tsuboki, and H. Nakamura, 2019: Primary factors behind the Heavy Rain Event of July 2018 and the subsequent heat wave in Japan. SOLA, 15A, 13-18.

Takaya, K., and H. Nakamura, 2001: A formulation of a phase-independent wave-activity flux for stationary and migratory quasigeostrophic eddies on a zonally varying basic flow. J. Atmos. Sci., 58, 608-627.

Takemura, K., Y. Kubo, and S. Maeda, 2017: Relation between a Rossby wave-breaking event and enhanced convective activities in August 2016. SOLA, 13, 120124.

Takemura, K., S. Wakamatsu, H. Togawa, A. Shimpo, C. Kobayashi, S. Maeda, and H. Nakamura, 2019: Extreme moisture flux convergence over western Japan during the Heavy Rain Event of July 2018. SOLA, 15A, 49-54.

Tam, C. Y., and T. Li, 2006: The origin and dispersion characteristics of the observed tropical summertime synoptic-scale waves over the western Pacific. Mon. Wea. Rev., 134, 1630-1646.

Wakabayashi, S., and R. Kawamura, 2004: Extraction of major teleconnection patterns possibly associated with anomalous summer climate in Japan. J. Meteor. Soc. Japan, 82, 1577-1588.

Xie, S.-P., and S. G. H. Philander, 1994: A coupled oceanatmosphere model of relevance to the ITCZ in the eastern Pacific. Tellus A, 46, 340-350. 